\title{
Aspectos tecnológicos de alimentos funcionais contendo probióticos
}

\author{
Maricê Nogueira de Oliveira*, Kátia Sivieri, João Henrique Alarcon Alegro, Susana Marta Isay Saad \\ Departamento de Tecnologia Bioquímico-Farmacêutica, Faculdade de Ciências Farmacêuticas, \\ Universidade de São Paulo.
}

*Correspondência:

M. N. Oliveira

Depto. Tecnologia Bioquímico-

Farmacêutica

FCF-USP

Av. Prof Lineu Prestes, 580. Bloco 16

05508-900. São Paulo, SP, Brasil.

E-mail: monolive@usp.br.
Os alimentos funcionais constituem hoje prioridade de pesquisa em todo mundo com a finalidade de elucidar as propriedades e os efeitos que estes produtos podem apresentar na promoção da saúde. As bactérias probióticas são microrganismos vivos que, quando consumidos, exercem efeitos benéficos sobre o hospedeiro conferindo propriedades à microbiota endógena. Algumas propriedades benéficas atribuídas às culturas probióticas necessitam de estudos mais controlados para serem definitivamente esclarecidas. Neste artigo são enfocados os aspectos tecnológicos dos probióticos, os efeitos associados ao consumo de produtos contendo probióticos e as principais cepas empregadas. São apresentados resultados experimentais originais para ilustrar os aspectos tecnológicos da fabricação de alimentos contendo probióticos buscando descrever suas limitações e alternativas.

\section{INTRODUÇÃO}

O efeito benéfico de determinados tipos de alimentos sobre a saúde do hospedeiro é conhecido há muito tempo. Apesar disso, o estudo desses alimentos, atualmente denominados alimentos funcionais, e de seus componentes responsáveis por esse efeito, tornou-se intenso apenas nos últimos anos.

São considerados alimentos funcionais aqueles que, além de fornecerem a nutrição básica, promovem a saúde. Esses alimentos possuem potencial para promover a saúde por meio de mecanismos não previstos pela nutrição convencional, devendo ser salientado que esse efeito restringe-se à promoção da saúde e não à cura de doenças. $\mathrm{O}$ termo nutracêutico diz respeito a um alimento ou ingrediente alimentar que proporciona benefícios médicos e/ou de saúde, incluindo prevenção e tratamento de doenças (Sanders, 1998).

A Tabela I enumera os aditivos alimentares considerados potencialmente funcionais, bem como o efeito funcional a eles atribuído.
Sanders (1998) enumerou seis causas para o aumento da procura por alimentos funcionais, a saber: os consumidores optam por prevenir ao invés de curar doenças; aumento dos custos médicos; os consumidores estão mais cientes sobre a relação entre a saúde e a nutrição; envelhecimento da população; desejo de combater os males causados pela poluição, por microrganismos e agentes químicos no ar, na água e nos alimentos e aumento das evidências científicas sobre a sua eficácia.

O objetivo primário dos alimentos funcionais é melhorar, manter e reforçar a saúde dos consumidores via alimentação. Consumidores e resultados científicos devem dar suporte às exigências para que um ingrediente ou alimento seja regulamentado. Autoridades ligadas à saúde em colaboração com a indústria de alimentos e a universidade têm a responsabilidade de realizar procedimentos para autorização das atribuições. O estabelecimento de lista positiva e a avaliação do dossiê contendo todos os resultados científicos avaliados devem ser analisados por um comitê multidisciplinar. O comitê deve promover um diálogo entre representantes científicos e da indústria vi- 
sando definir as principais justificativas que dão suporte às atribuições (Roberfroid, 2000).

O registro de alimentos funcionais é um problema difícil de ser resolvido, particularmente no que diz respeito aos dizeres da rotulagem. A discussão vem sendo feita no sentido de se estabelecer se o controle feito por meio da legislação existente é suficiente para a regulamentação dos alimentos funcionais ou se devem ser introduzidos registros específicos. No Japão, a definição legal de alimento funcional foi estipulada de acordo com o Sistema
“Alimento Destinado a Uso Específico de Saúde" (Food for Specific Health Use - FOSHU) da legislação de alimentos japonesa. De acordo com essa legislação, o alimento funcional é definido como aquele ao qual é atribuído um efeito positivo sobre a saúde (Lee et al., 1999). A Tabela II mostra a situação da legislação para alimentos funcionais em termos globais.

No Brasil, a legislação é recente (Brasil, 1999a, b, c, d). A resolução da Agência Nacional de Vigilância Sanitária do Ministério da Saúde (ANVS/MS) número 15 de

TABELA I - Principais aditivos alimentares com potencial funcional

\begin{tabular}{ll}
\hline Aditivos alimentares com potencial funcional & Efeito atribuído \\
\hline fibra de soja, bactérias probióticas, pectina & Redução do colesterol \\
$\beta$-caroteno, extratos de alho, esteróides, compostos fenólicos, "psyllium” & Combate a problemas cardíacos \\
alho, chá verde, bactérias probióticas, "psyllium" & Anti-carcinógenos \\
ácido g-aminobutírico, pectina & Anti-hipertensivo \\
cálcio, boro, fosfopeptídios de caseína & Prevenção da osteoporose \\
ácidos graxos $\omega$-3, extratos de gengibre, colágeno & Prevenção da artrite \\
licopeno, frutas e verduras contendo anti-oxidantes & Alteração do dano oxidativo \\
bactérias probióticas, zinco ionizado, extrato de "elderberry" & Agentes anti-infecciosos \\
\hline
\end{tabular}

FONTE: Adaptado de Sanders, 1998.

TABELA II - Situação da legislação para alimentos funcionais em termos globais

\begin{tabular}{lll}
\hline & Padrão para Alimento Funcional & Posição sobre Atribuição de Efeitos sobre a Saúde \\
\hline Codex Alimentarius & Não regulamentado & Não permitido \\
Japão & FOSHU & Permitido, seguindo as normas do FOSHU \\
Estados Unidos & Não regulamentado & Permitido \\
Canadá & Não regulamentado & Permitido \\
& & Sendo revisto \\
Austrália & Não regulamentado & Não permitido \\
Nova Zelândia & & Sendo revisto \\
União Européia & Não regulamentado & Não permitido \\
Suécia & Não regulamentado & $\begin{array}{l}\text { Permitidas algumas atribuições específicas - } \\
\text { estipuladas por um grupo de especialistas e indústrias }\end{array}$ \\
Holanda & & $\begin{array}{l}\text { Atribuições específicas auto-regulamentadas, } \\
\text { aprovadas por um grupo de especialistas }\end{array}$ \\
\hline
\end{tabular}

FONTE: Adaptado de Lee et al., 1999. 
30/04/1999 institui junto à Câmara Técnica de Alimentos, a Comissão de Assessoramento Técnico Científico de alimentos funcionais e novos alimentos. Esta passa a ter a incumbência de prestar consultoria e assessoramento em matérias relacionadas com os alimentos funcionais e novos alimentos, bem como a segurança de consumo e a alegação de função nos rótulos. A portaria de número 16 de 30/04/1999 corresponde ao regulamento técnico de procedimentos para registro de alimentos e/ou de novos ingredientes. Alimentos ou ingredientes novos são os alimentos ou substâncias sem histórico de consumo no país, ou alimentos com substâncias já consumidas, e que, entretanto venham a ser adicionadas ou utilizadas em níveis muito superiores aos atualmente observados nos alimentos utilizados na dieta regular. Uma avaliação objetiva de segurança deve ser feita por uma Comissão de Assessoramento Técnico Científica em alimentos funcionais e novos alimentos constituída pela ANVS. A portaria ANVS/ MS número 18 de 30/04/1999 dá as diretrizes básicas para a análise e comprovação de propriedades funcionais e/ou de saúde alegadas na rotulagem de alimentos. São discutidos três tipos de alegações sobre o conteúdo, a função metabólica e de saúde, sendo permitidas apenas de redução de risco. A alegação de propriedades funcionais ou de saúde é permitida em caráter opcional. O alimento ou ingrediente que alegar propriedades funcionais ou de saúde pode, além de funções nutricionais básicas, quando se tratar de nutriente, produzir efeitos metabólicos, fisiológicos e/ou efeitos benéficos à saúde, devendo ser seguro para o consumo sem supervisão médica.

A portaria ANVS/MS número 19 de 30/04/1999 regulamenta os procedimentos para o registro de alimento com alegação de propriedades funcionais e/ou de saúde em sua rotulagem. Dentre a documentação necessária estão previstos o texto e a cópia do esboço com os dizeres da rotulagem do produto e as diretrizes básicas para análise e comprovação de propriedade funcional ou de saúde alegadas na rotulagem do produto. Alimentos que já possuem registro e que queiram fazer alegações de propriedades funcionais, além de adotar os procedimentos administrativos para a modificação de fórmula e de rotulagem, devem apresentar o relatório técnico-científico.

\section{As bactérias probióticas}

A suplementação de componentes com atividade reconhecidamente benéfica à saúde, como cálcio e vitaminas, constituíam os alimentos funcionais de primeira geração. Nos últimos anos, por outro lado, esse conceito voltou-se principalmente para aditivos alimentares, que podem exercer efeito benéfico sobre a composição da microbiota intestinal. Os prebióticos e os probióticos são atualmente os aditivos alimentares que compõem esses alimentos funcionais (Ziemer, Gibson, 1998).

Os probióticos são ingredientes não digeríveis incorporados aos alimentos no sentido de selecionar determinadas bactérias da microbiota intestinal, por meio de sua atuação como um substrato seletivo no nível do cólon (Ziemer, Gibson, 1998; Lee et al., 1999).

Determinadas bactérias láticas e outras bactérias, além de atuarem favoravelmente no produto alimentício ao qual foram adicionados, fazem parte dos microrganismos capazes de exercer efeitos benéficos no hospedeiro. São os denominados microrganismos probióticos. Um microrganismo probiótico deve necessariamente sobreviver às condições adversas do estômago e colonizar o intestino, mesmo que temporariamente, por meio da adesão ao epitélio intestinal (Ziemer, Gibson, 1998; Lee et al., 1999).

Em condições normais, inúmeras espécies de bactérias estão presentes no intestino, a maioria delas anaeróbias estritas. Essa composição torna o intestino capaz de responder a possíveis variações anatômicas e físico-químicas (Lee et al., 1999). A microbiota intestinal exerce influência considerável sobre série de reações bioquímicas do hospedeiro. Paralelamente, quando em equilíbrio, impede que microrganismos potencialmente patogênicos nela presentes exerçam seus efeitos patogênicos. Por outro lado, o desequilíbrio dessa microbiota pode resultar na proliferação de patógenos, com conseqüente infecção bacteriana (Ziemer, Gibson, 1998).

Segundo Goldin (1998), a palavra probiótico foi introduzida por Lilley e Stillwell, em 1965, para descrever microorganismos que desempenham atividades benéficas. Os probióticos são definidos como « microorganismos vivos que, quando são consumidos, agem no trato gastrintestinal do organismo hospedeiro melhorando o balanço microbiano intestinal » (Kurmann, 1988; Fuller, 1989, 1994). Considerando, como é admitido comumente, que a fermentação pode melhorar o digestibilidade de alimentos e produzir vitaminas e co-fatores nos produtos alimentícios, existem atualmente alguns trabalhos científicos que permitem afirmar que as bactérias probióticas têm um efeito benéfico na saúde humana (Gilliland, 1989).

Holzapfel et al. (1998) optam pela definição de probióticos proposta por Havenaar et al. (1992), a qual define probióticos como culturas puras ou mistas de microrganismos vivos (bactérias láticas e outras bactérias ou leveduras aplicadas como células secas ou em um produto fermentado) que quando aplicadas aos animais ou ao homem, tem efeitos benéficos ao hospedeiro promoven- 
do o balanço de sua microbiota intestinal. Os autores discutem que esta definição é mais ampla e vantajosa, pois não restringe os efeitos probióticos à microbiota intestinal, mas também às comunidades microbianas de outras partes do corpo; os probióticos podem consistir de uma ou mais espécies; podem ser aplicadas aos animais e ao homem.

\section{Efeitos biológicos dos probióticos}

Fuller (1989) enumerou três possíveis mecanismos de atuação dos probióticos, sendo o primeiro deles a supressão do número de células viáveis mediante produção de compostos com atividade antimicrobiana, a competição por nutrientes e a competição por sítios de adesão. O segundo desses mecanismos seria a alteração do metabolismo microbiano, pelo aumento ou diminuição da atividade enzimática. O terceiro seria o estímulo da imunidade do hospedeiro, por meio do aumento dos níveis de anticorpos e o aumento da atividade dos macrófagos. Segundo Naidu e Clemens (2000), o espectro de atividade dos probióticos pode ser dividido em efeitos nutricionais, fisiológicos e antimicrobianos.

Diversos autores vêm sugerindo possíveis efeitos benéficos de culturas probióticas sobre a saúde do hospedeiro. Entre esses efeitos benéficos, merecem destaque o controle das infecções intestinais, o estímulo da motilidade intestinal, com conseqüente alívio da constipação intestinal, a melhor absorção de determinados nutrientes, a melhor utilização de lactose e o alívio dos sintomas de intolerância a esse açúcar, a diminuição dos níveis de colesterol, o efeito anticarcinogênico e o estímulo do sistema imunológico, pelo estímulo da produção de anticorpos e da atividade fagocítica contra patógenos no intestino e em outros tecidos do hospedeiro, além da exclusão competitiva e da produção de compostos antimicrobianos (Sandine et al., 1972; Gilliland, Speck, 1977; Kim, Gilliland, 1983; Fuller, 1989; Gilliland, 1989; Tejada-Simon et al., 1999; Lee et al., 1999; Gomes, Malcata, 1999; Shortt, 1999; Sreekumar, Hosono, 2000; Naidu, Clemens, 2000).

Lee et al. (1999) e Gomes, Malcata (1999) enumeraram os diferentes estudos realizados no sentido de elucidar os efeitos benéficos das culturas probióticas sobre o hospedeiro. Segundo Gomes e Malcata (1999), os resultados desses estudos são bastante variáveis, chegando a ser contraditórios em alguns casos. Os autores concluíram que algumas propriedades benéficas atribuídas às culturas probióticas necessitam de estudos mais controlados para serem definitivamente estabelecidas.

Como conseqüência da falta de estudos científicos clínicos conclusivos foi criado, em 1996, o projeto
PROBDEMO - "Demonstration of the Nutritional Functionality of Probiotic Foods", envolvendo universidades, centros de pesquisa e indústrias de toda a Europa. A principal meta desse estudo colaborativo recém-concluído era demonstrar a influência dos probióticos sobre a microbiota intestinal e a saúde humana, empregando-se estudos clínicos pilotos controlados. Os estudos, finalizados em fevereiro de 2000, tinham como alvo tanto indivíduos saudáveis quanto com problemas de saúde para os quais o tratamento com probióticos apresentava um embasamento teórico para a ação profiláctica ou terapêutica (Mattila-Sandholm, 1999).

Segundo Mattila-Sandholm (1999), os estudos do projeto PROBDEMO demonstraram que alguns probióticos podem influenciar na composição da microbiota intestinal e modular o sistema imunológico do hospedeiro, resultando em efeitos benéficos mensuráveis sobre a sua saúde, incluindo o controle de eczema atópico de criança com alergia alimentar. Os autores relataram que o emprego de probióticos selecionados mostrou-se bastante promissor no controle de doenças intestinais inflamatórias e de infecções em crianças e idosos.

Em um estudo envolvendo 80 indivíduos observouse que tanto o leite como o iogurte foram eficazes como veículos de uma cepa de $L b$. salivarius. Nesse estudo, o leite era aparentemente mais eficaz como veículo, uma vez que o nível de probiótico viável nas fezes dos indivíduos que receberem leite contendo probiótico era significativamente superior. Entretanto, os indivíduos que receberam iogurte contendo probiótico apresentaram respostas mais acentuadas no que diz respeito à modulação da microbiota intestinal (redução da contagem de enterococus e clostrídios) e indução da resposta imune no nível de mucosa (Mattila-Sandholm et al. 1999).

As bactérias probióticas só apresentam efeitos biológicos no ambiente intestinal se atingirem um número mínimo. Por exemplo, o número de L. rhamnosus para reduzir significativamente a ocorrência da chamada diarréia dos viajantes é de $10^{9} \mathrm{UFC} / \mathrm{g}$ (Oksanen et al., 1990). Assim, considerando um consumo de produtos lácteos de $100 \mathrm{~g}$, estes devem conter pelo menos $10^{7} \mathrm{UFC} / \mathrm{g}$ de bactérias probióticas viáveis no momento da compra do produto. Este é o número recomendável por diversos autores (Rybka, Fleet, 1997; Vinderola, Renheimer, 2000).

\section{Seleção de bactérias probióticas}

A seleção de bactérias probióticas tem como base os seguintes critérios preferenciais: o gênero ao qual pertence a bactéria ser de origem humana, a estabilidade frente ao ácido e à bile, a capacidade de aderir à mucosa intestinal, 
a capacidade de colonizar, ao menos temporariamente, o trato gastrintestinal humano, a capacidade de produzir compostos antimicrobianos e ser metabolicamente ativo no nível do intestino. Ainda, a segurança para uso humano, ter histórico de não patogenicidade e não devem estar associadas a outras doenças tais como endocardite, além da ausência de genes determinantes da resistência aos antibióticos (Collins et al., 1998; Lee et al., 1999; Saarela et al., 2000). A Figura 1 mostra a árvore decisória empregada para o desenvolvimento de novos probióticos.

Segundo o FDA, algumas bactérias são permitidas para o emprego em alimentos e entre elas estão as probióticas. A Tabela III apresenta as principais cepas de bactérias probióticas empregadas. Entre os microrganismos empregados como probióticos, destacam-se as bactérias pertencentes aos gêneros Bifidobacterium e Lactobacillus e, em menor escala, as bactérias Enterococcus faecium e Streptococcus thermophilus. Dentre as bactérias pertencentes ao gênero Bifidobacterium, destacam-se $B$. bifidum, $B$. breve, $B$ infantis, B. lactis, $B$. longum e B.thermophilum. Dentre as bactérias láticas pertencentes ao gênero Lactobacillus, destacam-se L. acidophilus, L. delbrueckii subsp. bulgaricus, L. helveticus, L. casei - subsp. paracasei e subsp. tolerans, $L$. paracasei, $L$. fermentum, $L$. reuteri, $L$. johnsonii, L. plantarum, L. rhamnosus e L. salivarius (Collins et al., 1998; Lee et al., 1999; Sanders, Klaenhammer, 2001).

Segundo Lee et al. (1999), as bactérias mais amplamente utilizadas pela indústria de alimentos pertencem ao grupo das bactérias láticas, embora algumas bifidobactérias e leveduras também sejam utilizadas. Klein et al. (1998), por outro lado, relatam que o gênero Bifidobacterium também é considerado como pertencente ao grupo das bactérias láticas devido a propriedades bioquímicas e fisiológicas e nichos ecológicos (inclusive o trato gastrintestinal) em comum com os outros gêneros de bactérias láticas. Esse fato ocorre apesar dos gêneros mais importantes do grupo das bactérias láticas - Lactobacillus, Lactococcus, Enterococcus, Streptococcus, Pediococcus, Leuconostoc, Weissela, Carnobacterium e Tetragenococcus - pertencerem ao filo das bactérias Gram-positivas com um baixo $(<50 \%$ ) conteúdo de $\mathrm{C}+\mathrm{G}$ (guanina mais citosina), ao contrário do que ocorre com o gênero Bifidobacterium.

O emprego de bactérias láticas em alimentos é de longa data e a maioria das cepas empregadas são consideradas microrganismos comensais, sem potencial patogênico. Dentre esses microrganismos, as bactérias pertencentes ao gênero Lactobacillus são mais freqüentemente consideradas seguras ou reconhecidamente seguras (GRAS - "generally recognized as safe"). Por outro lado, certas bactérias do gênero Streptococcus e Enterococcus são patógenos oportunistas (Collins et al., 1998; Lee et al., 1999).

Com base em estudos taxonômicos e fisiológicos de bactérias láticas probióticas Klein et al. (1998) concluíram que a maioria das culturas probióticas empregadas em produtos comerciais não possuem a designação apropriada de espécie e que a diferenciação adequada entre as espécies é essencial por razões de segurança em termos de saúde. Assim, segundo os autores, muitas bactérias relatadas como sendo $L$. acidophilus são, na verdade, $L$. johnsonii ou L. gasseri; praticamente todas as cepas de $L$.

TABELA III - Cepas comumente empregadas em produtos probióticos

\begin{tabular}{lll}
\hline Lactobacillus spp. & Bifidobacterium spp. & Outras \\
\hline L. acidophilus & B. bifidum & Streptococcus thermophilus \\
L. plantarum & B. longum & Lactococcus lactis subsp. lactis \\
L. rhamnosus & B. infantis & Lactococcus lactis subsp. cremoris \\
L. brevis & B. breve & Enterococcus faecium \\
L. delbreuckii subsp. bulgaricus (LB) & B. adolescentis & $\begin{array}{l}\text { Leuconostoc mesenteroides } \text { subsp. } \\
\text { dextranium }\end{array}$
\end{tabular}

L. fermentum

L. helveticus

L. johnsonii
Propionibacterium freudenreichii

Pediococcus acidilactici

Saccharomyces boulardii

FONTE : Collins et al., 1998. 
casei são L. paracasei e muitas cepas denominadas $B$. longum são cepas de $B$. animalis em produtos lácteos.

O’Brien et al. (1999) salientam que, particularmente no caso de Bifidobacterium, é necessária a identificação apropriada das cepas a serem empregadas em produtos contendo probióticos, uma vez que três de suas espécies $B$. dentium, $B$. denticolens e $B$. inopinatum estão associadas à cárie dentária e não devem ser utilizadas em produtos alimentícios. Os autores relataram a existência de inúmeras evidências de que os microrganismos probióticos empregados são seguros e que, na maioria dos casos de infecção por bactérias láticas descritos, o microrganismo envolvido originou-se da própria microbiota do paciente.

Estudos clínicos controlados com lactobacilos e bifidobactérias não revelaram efeitos maléficos causados por esses microrganismos. Efeitos benéficos causados por essas bactérias foram observados durante o tratamento de infecções intestinais, incluindo a estabilização da barreira da mucosa intestinal, prevenção da diarréia e melhora da diarréia infantil e da associada ao uso de antibióticos (Lee et al., 1999).

Paralelamente, apesar de muitas cepas de bactérias láticas, particularmente as de Lactobacillus spp., apresentarem resistência contra determinados antibióticos, a mesma normalmente não é mediada por plasmídios, não sendo transmissível. Entretanto, há descrição de cepas portadoras de plasmídios de resistências, particularmente cepas de Enterococcus resistentes à vancomicina. Cepas com plasmídios de resistência não devem ser empregadas como probióticos humanos ou animais, uma vez que são capazes de transmitir os fatores de resistência para bactérias patogênicas, dificultando a cura de infecções (Salminen et al., 1998; O'Brien et al., 1999; Saarela et al., 2000).

Apesar das culturas probióticas de Lactobacillus spp. e de Bifidobacterium spp. serem consideradas GRAS, é necessária a determinação da segurança na utilização da cepa antes do lançamento e da divulgação de um novo produto. Assim, uma avaliação crítica da segurança tornará os benefícios dos probióticos acessíveis ao consumidor (Salminen et al., 1998; O’Brien et al., 1999).

\section{ASPECTOS TECNOLÓGICOS DO EMPREGO DE PROBIÓTICOS}

Para a utilização de culturas probióticas na tecnologia de fabricação de produtos alimentícios, além da seleção de cepas probióticas para uso humano mediante critérios mencionados anteriormente, as culturas devem ser empregadas com base no seu desempenho tecnológico. Culturas probióticas com boas propriedades tecnológicas

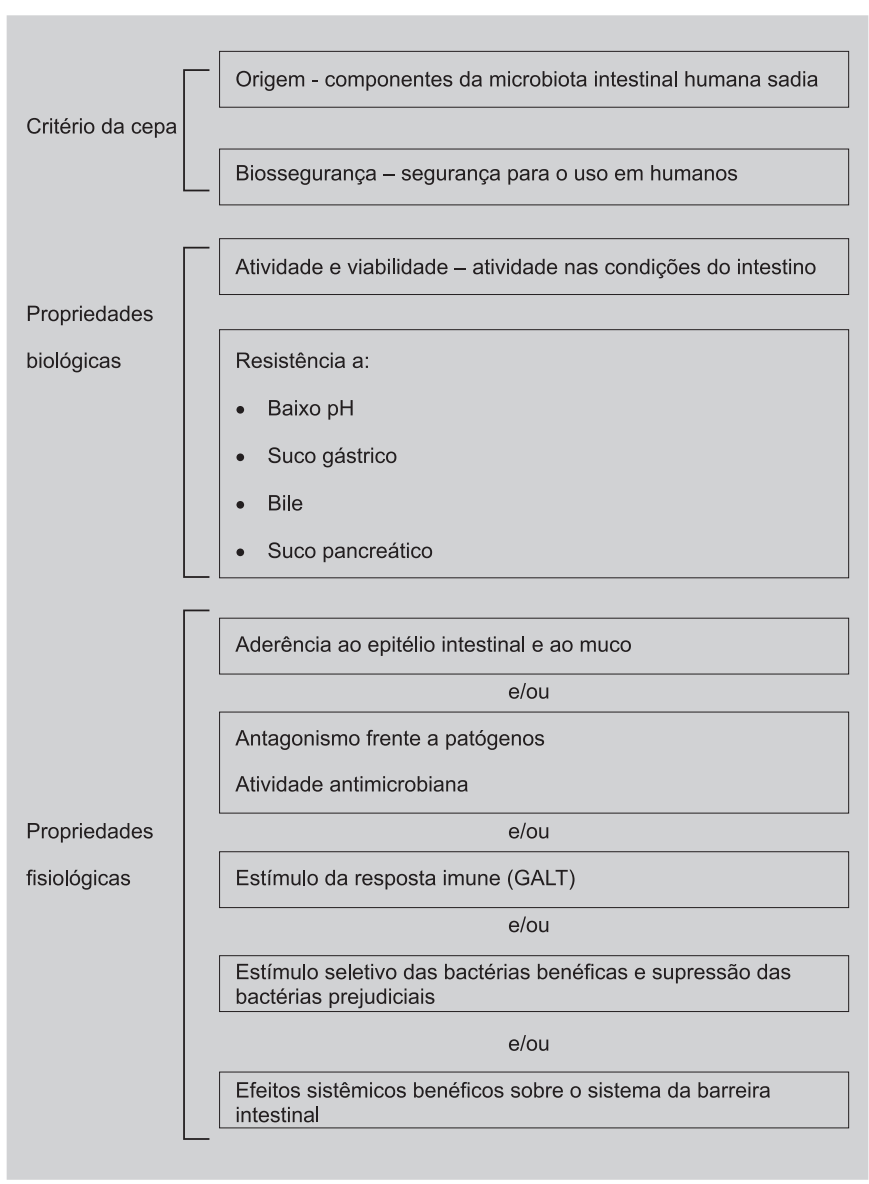

FIGURA 1 - Árvore decisória para o desenvolvimento de novos probióticos (Lee et al., 1999).

devem apresentar boa multiplicação no leite, promover propriedades sensoriais adequadas no produto e serem estáveis e viáveis durante o armazenamento. Desta forma, podem ser manipuladas e incorporadas em produtos alimentícios sem perder a viabilidade e a funcionalidade, resultando em produtos com textura e aroma adequados.

\section{Enriquecimento do leite}

Apesar do leite ser um meio rico do ponto de vista nutricional, as bactérias probióticas crescem lentamente no leite devido principalmente à falta de atividade proteolítica (Klaver et al., 1993). A incorporação de micronutrientes como peptídeos e aminoácidos e de outros fatores de crescimento pode ser necessária para reduzir o tempo de fermentação e propiciar viabilidade às bactérias probióticas. A Figura 2 exemplifica o efeito do enriquecimento do leite sobre o perfil de acidificação. Observase que no caso do leite inoculado com $1 \%$ de $L b$. acidophilus, o tempo para atingir valor de $\mathrm{pH}$ 5,0 é da 
ordem de aproximadamente $21,2 \mathrm{~h}$, enquanto no leite enriquecido, este tempo diminui para $11,2 \mathrm{~h}$ ou seja, ocorre uma diminuição de cerca 10,0 h (Figura 2a). Por outro lado, não se observou alteração no tempo para atingir $\mathrm{pH}$ 5,0 para o leite e o leite enriquecido inoculado com a mesma proporção de L. rhamnosus. Este foi da ordem de 26,1 h (Figura 2b).

\section{a) L. acidophilus}

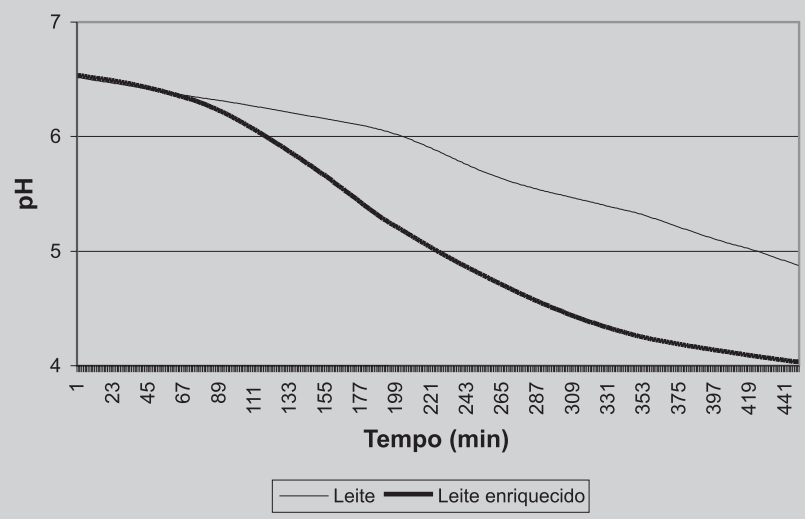

b) L. rhamnosus

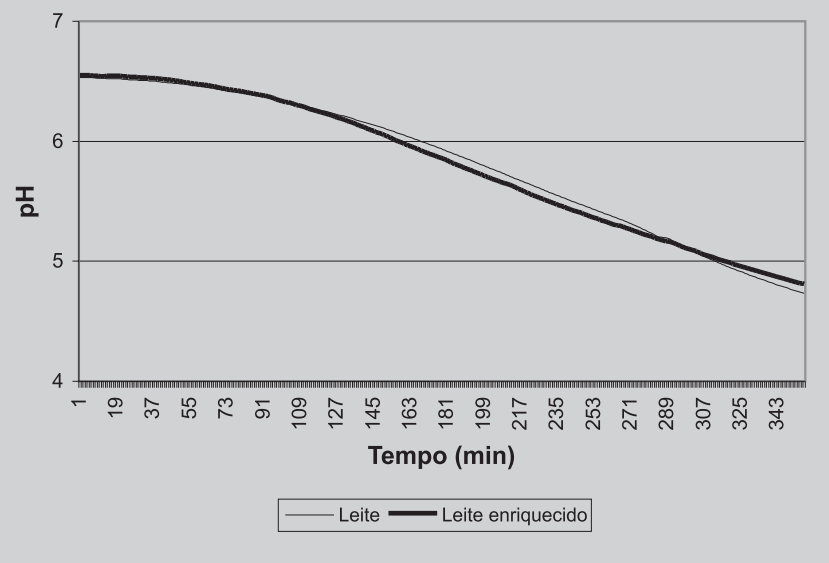

FIGURA 2 - Curva de acidificação do leite e do leite enriquecido com $2 \%$ de soro em pó inoculado com $0,5 \%$ de L. acidophilus ou $0,5 \%$ de L. rhamnosus em cultura pura a $42{ }^{\circ} \mathrm{C}$. Dados originais obtidos de acordo com metodologia descrita em Oliveira et al., 2001.

Dave, Shah (1998) estudaram o efeito da adição de cisteína, soro em pó, concentrado protéico de soro, caseína hidrolizada ou triptofano na viabilidade de bactérias probióticas em iogurte. Com exceção do soro em pó, as outras proteínas adicionadas melhoraram a viabilidade de bifidobacteria. Saxelin et al. (1999) recomendaram a adi- ção de $2 \%$ de glicose ao leite para estimular o crescimento e a produção de ácido de L. rhamnosus e de L. paracasei F19. Os autores relataram que extrato de levedura estimulava a multiplicação da maioria das cepas e não afetava a multiplicação de L. rhamnosus, enquanto a adição simultânea de glicose e extrato de levedura resultava em maior estímulo da multiplicação desse microrganismo, comparado à adição apenas de glicose. A adição de frações protéicas do leite resultou no estímulo da multiplicação da maioria das cepas.

Em geral, as bactérias probióticas são exigentes em nutrientes. L. acidophilus apresenta necessidades nutricionais complexas. Aminoácidos e fatores de crescimento como pantotenato de cálcio, ácido fólico, niacina e riboflavina são essenciais (Du Plessis et al., 1996). $L$. rhamnosus é um lactobacilo atípico porque não fermenta a lactose, a maltose ou a sacarose e fermenta somente a ramnose muito lentamente (Goldin, 1998). Todas as espécies de bifidobactéria crescem bem no leite e fermentam lactose. A necessidade de diversos fatores de crescimento para a multiplicação de bifidobactéria in vitro foi relatada, bem como a necessidade de tiamina, piridoxina, ácido fólico e cianocobalamina (Modler, 1994; Arunachalam, 1999). Segundo Shah e Ravula (2000), níveis de 12 e de $16 \%$ de sacarose inibem o crescimento de L. acidophilus e Bifidobacterium spp.

\section{Emprego de co-culturas}

O emprego de bactérias probióticas em cultura pura é inviável industrialmente e pode ser ilustrado pela Figura 3, na qual se apresenta a curva de acidificação do leite por L. acidophilus em cultura pura. Pode-se observar que o tempo para o leite enriquecido atingir $\mathrm{pH} 4,5$ é da ordem de 8,2 h. Saxelin et al. (1999) relataram que quando culturas probióticas eram empregadas isoladamente com essa finalidade, o pH do leite continuava acima de 5,4 após 20 horas a $42{ }^{\circ} \mathrm{C}$. Comportamento diferente foi observado quando as cepas L. johnsonii La1 e B. lactis BB12 foram empregadas em co-cultura, situação em que o leite fermentado atingiu um $\mathrm{pH}$ igual ou inferior a 4,5 após 20 horas. Samona et al. (1996) mostraram que cepas de bifidobactéria não poderiam crescer na presença de culturas do iogurte, mas com uma composição adequada da cocultura, a diminuição do número de colônias de bifidobactéria poderia ser evitada.

Apesar das dificuldades, o emprego de cultura probióticas puras com a finalidade de se obter produtos lácteos fermentados é possível, dependendo da cepa, do nível de inoculação e da adição de determinados ingredientes, que irão facilitar a multiplicação da(s) cultura(s) 
probiótica(s) e, conseqüentemente, o processo fermentativo.

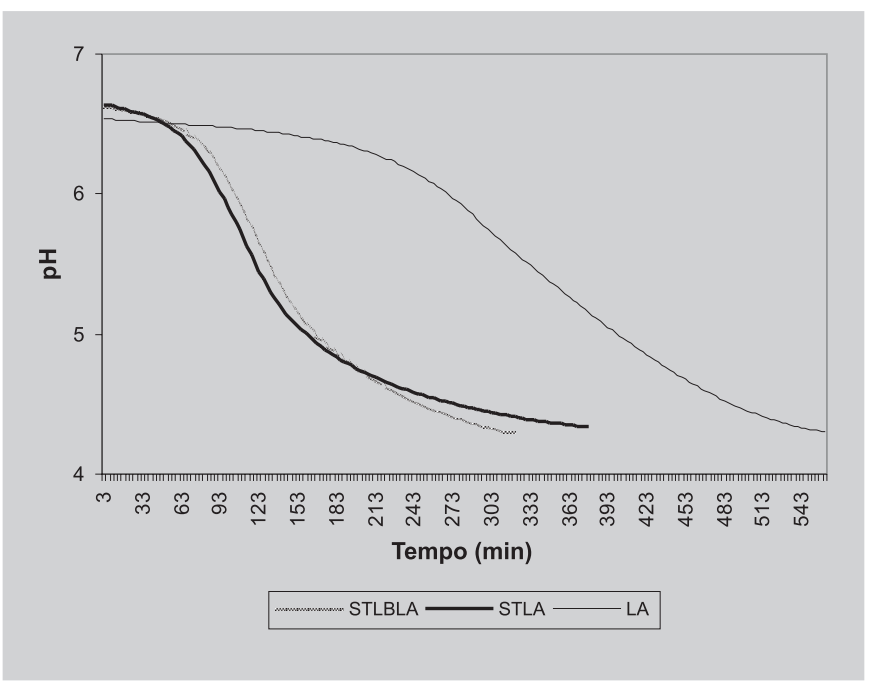

FIGURA 3 - Curva de acidificação do leite com $L$. acidophilus (LA; 0,5\%) em cultura pura e mista com $S$. thermophilus e L. bulgaricus (STLBLA; 0,125\%: 0,125\%: 0,250 ) e $S$. thermophilus (STLA; 0,250\%: 0,250\%). Dados originais obtidos de acordo com metodologia descrita em Oliveira et al., 2001.

A prática atual para a fabricação de leites fermentados contendo probióticos é de adicionar bactérias convencionais do iogurte como L. bulgaricus e S. thermophilus para facilitar o processo de fermentação (Samona, Robinson, 1994; Shah, Lankaputhra, 1997; Dave, Shah, 1998). Entretanto, L. bulgaricus também produz ácido lático durante o armazenamento por meio de mecanismo denominado pós-acidificação, que é reconhecido por afetar a viabilidade das bactérias probióticas (Dave, Shah, $1997 \mathrm{a}, \mathrm{b})$.

Em função da perda de viabilidade, o emprego de culturas probióticas associadas a culturas de suporte compostas, de preferência, de $S$. thermophilus ou de outra cultura de iogurte ou culturas mesofílicas com diferentes combinações de cepas de Lactococcus é aconselhável. Em determinados casos, a combinação de cepas de culturas probióticas com culturas de iogurte resulta na diminuição da contagem de cultura probiótica durante a vida de prateleira do produto, enquanto que em outros essa diminuição não ocorre. Esse fato demonstra que a seleção de uma cultura de suporte apropriada para cada cultura probiótica é fundamental para a obtenção de produtos frescos fermentados com boa sobrevivência de culturas probióticas durante sua vida de prateleira (Saxelin et al., 1999; Saarela et al., 2000).
O emprego de co-culturas compostas com as bactérias convencionais do iogurte e L. acidophilus (STLBLA) e $S$. thermophilus e L. acidophilus na acidificação do leite enriquecido é mostrada na Figura 3. Com o emprego das co-culturas STLBLA e STLA os tempos para atingir o valor de $\mathrm{pH}$ 4,5 foram de 4,2 e 4,6 h, respectivamente. Evidenciou-se que o emprego de co-culturas permite a fermentação em tempos aproximadamente duas vezes menores do que aqueles nos quais são utilizadas culturas puras, tornando-se adequado para a indústria.

A combinação mais apropriada de uma cultura starter a uma bactéria probiótica específica deve ser determinada por processo de seleção que irá avaliar o impacto das diferentes culturas starter sobre as propriedades sensoriais e a sobrevivência das bactérias probióticas. Preferência deve ser dada a uma cultura starter termofílica, uma vez que a maioria dos probióticos multiplica-se bem a $37^{\circ} \mathrm{C}$, e a uma cultura probiótica capaz de multiplicar-se durante a fermentação. Adicionalmente, a taxa de multiplicação da cultura starter deve ser moderada, permitindo a multiplicação da bactéria probiótica, e a cultura starter deve produzir compostos que favoreçam a multiplicação da cultura probiótica ou promover redução da tensão de oxigênio (Saarela et al., 2000).

A temperatura de fermentação normalmente recomendada para a fabricação de produtos contendo culturas probióticas é de 37 a $40{ }^{\circ} \mathrm{C}$, uma vez que nesta faixa de temperatura a maioria das cepas probióticas se multiplica. Em determinados casos, as cepas probióticas são adicionadas ao leite fermentado após a fermentação, o que vem a encarecer o produto. Entretanto, essa adição posterior não propicia a multiplicação do probiótico, podendo, inclusive, resultar em diminuição de sua viabilidade. Assim sendo, é recomendável a adição do probiótico antes ou concomitantemente à adição da cultura starter (Saarela et al., 2000).

Quando as exigências nutricionais e as condições de cultivo (temperatura e atmosfera, por exemplo) das diferentes cepas empregadas são muito diferentes, pode-se lançar mão do cultivo isolado das culturas com sua posterior adição nas proporções desejadas. A fermentação do leite isoladamente com cada cepa, seguida da mistura dos diferentes leites fermentados também pode ser feita (Svensson, 1999).

\section{Propriedades sensoriais e de textura}

As características sensoriais desempenham papel importante na aceitação do produto pelo consumidor. Iogurte apresenta frágil mas distinguível flavor influenciado por diferente fatores como a viscosidade, a presença de 
compostos não voláteis e o aroma (Ott et al., 2000).

Diacetil e acetaldeído são dois compostos que participam do aroma de diversos produtos lácteos (Stien et al., 1999). Diversos compostos de flavor foram isolados de produto tipo iogurte; entretanto, somente acetaldeído, etanol, acetona, diacetil e 2-butanona foram encontrados em quantidades substanciais (Kneifel et al., 1993).

Acetaldeído é considerado como o composto mais proeminente para o aroma típico do iogurte (Bottazzi et al., 1973; Kneifel et al., 1993, Stien et al., 1999). As concentrações de acetaldeído podem variar de um produto a outro (Stien et al., 1999); produtos com teores de acetaldeído inferiores a 10 ppm são considerados como de baixa intensidade de flavor (Ott et al., 2000).

A Figura 4 mostra a concentração de acetaldeído em iogurtes preparados com culturas puras e co-culturas de probióticos após um dia e sete dias de armazenamento a $4{ }^{\circ} \mathrm{C}$. Observa-se que com o emprego de culturas puras, a concentração de acetaldeído é praticamente inexistente para o iogurte preparado com L. rhamnosus enquanto foi da ordem de $10 \mathrm{ppm}$ em iogurte preparado com $L$. acidophilus após um dia de armazenamento, caindo praticamente a zero após sete dias. Usando-se co-culturas, os teores de acetaldeído foram maiores, variando de 10,0 a 15,0 ppm após um dia de armazenamento. Após sete dias, a concentração diminuiu, variando de 2,2 a 13,8 ppm.
Pode-se notar, ainda, que a estabilidade do aroma é maior quando se empregam co-culturas contendo $L$. bulgaricus. Em todos os casos, a concentração de acetaldeído presente nos iogurtes contendo bactérias probióticas é inferior àquela fabricada com a cultura clássica do iogurte (Figura 4).

Em geral, produtos lácteos contendo Lb. acidophilus são caracterizados como pobres em flavor devido ao fato de que esta bactéria apresenta uma álcool desidrogenase, que converte acetaldeído em etanol (Marshall et al., 1982). Hickey et al. (1983) observaram que a enzima treonina aldolase pode converter o excesso de treonina a acetaldeído via glicina, sem aumento concomitante na atividade da álcool desidrogenase. Assim, o conteúdo de acetaldeído em iogurtes contendo L. acidophilus pode ser aumentado pela fortificação do leite com treonina (Marshall, 1987).

Kwak et al. (1996) verificaram, em iogurte preparado com L. acidophilus, Bifidobacterium bifidum e $S$. thermophilus, que o teor de acetaldeído aumenta acentuadamente entre 3 e $6 \mathrm{~h}$ após o início da fermentação, quando o $\mathrm{pH}$ do meio está entre 4,3 e 4,8. O mesmo foi de 0,059 a 17,9 ppm na primeira e sexta hora de fermentação, respectivamente. Bolin et al. (1998) constataram que o nível de acetaldeído variou de 3,9-6,4 mg/L em leites incubados durante $18 \mathrm{~h}$ e diminuiu $33 \%$ em média após 24 h de incu-

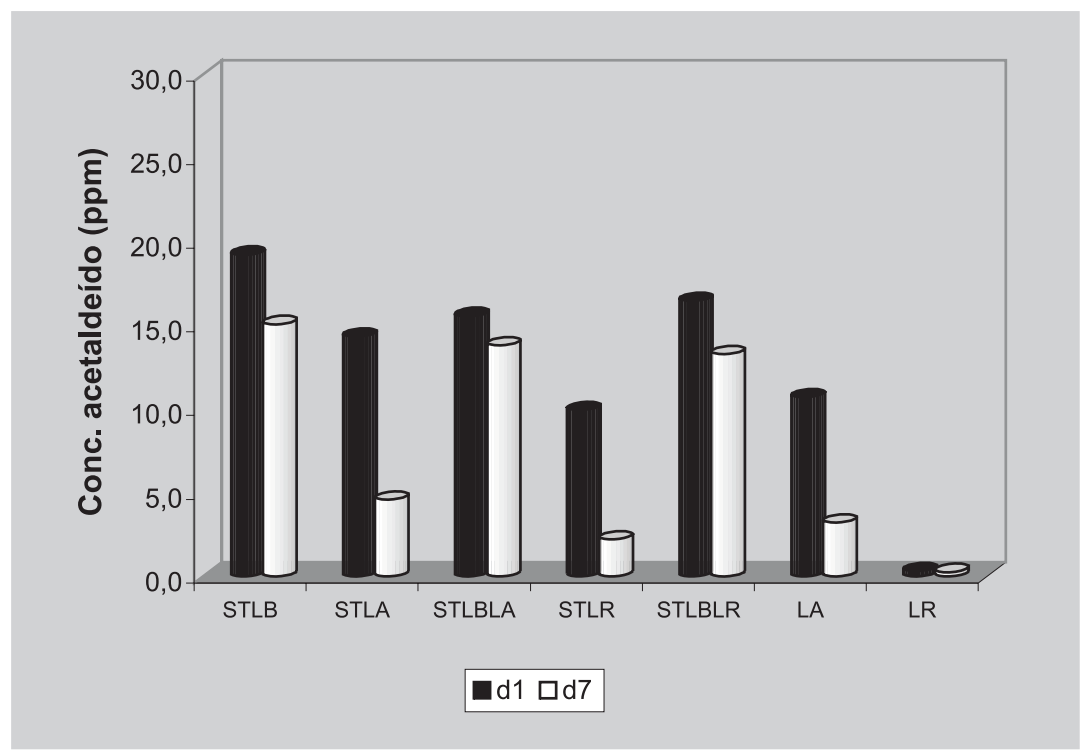

FIGURA 4 - Concentração de acetaldeído em iogurtes preparados com culturas puras e mistas de probióticos após um dia (d1) e 7 dias (d7) de conservação a $4{ }^{\circ} \mathrm{C}$. (STLB : 0,250\% S. thermophilus $+0,250 \%$ L. bulgaricus ; STLA : $0,250 \%$ Str. thermophilus $+0,250 \%$ L. acidophilus ; STLBLA : 0,125\% S. thermophilus $+0,125 \%$ L. bulgaricus $+0,250 \% L$. acidophilus ; STLR : 0,250\% S. thermophilus $+0,250 \%$ L. rhamnosus ; STLBLR : 0,125\% S. thermophilus $+0,125 \%$ L. bulgaricus $+0,250 \%$ L. rhamnosus; LA : 0,5\% L. acidophilus ; LR : 0,5\% L. rhamnosus). Dados originais: o teor de acetaldeído foi determinado mediante kit enzimático (Boehringer, Manhein, Alemanha). 
bação. As cepas de L. acidophilus estudadas (B, V-74, $\mathrm{CH}-2$ e CH-5) mostraram diferentes capacidades de produção de acetaldeído. A cepa V-74 foi aquela que apresentou a melhor produtividade.

Segundo Gupta et al. (1997), o teor de acetaldeído em iogurtes regulares $(29,40 \pm 7,53 \mathrm{ppm})$ é três vezes superior àquele preparado com $L$. acidophilus $(16,60 \pm$ $3,80 \mathrm{ppm}$ ). Stien et al. (1999) encontraram valores de acetaldeído de $42,10 \mathrm{mg} / \mathrm{kg}$ para iogurtes naturais e e $8,62 \mathrm{mg} / \mathrm{kg}$ para leite fermentado contendo bifidus. Roushdy et al. (1996) preparam leite de búfala inoculado com $3 \%$ de L. acidophilus e, avaliando o teor de acetaldeído no produto durante 14 dias, encontraram valores entre 41 e $53 \mathrm{mg} / \mathrm{mL}$. O conteúdo em acetaldeído aumentou nos 7 primeiros dias de armazenamento, diminuindo ao longo do período de estocagem.

Outro atributo importante na aceitação do iogurte pelo consumidor é sua característica de textura. Segundo Rossi (1983) e O'Neil et al. (1979), o iogurte deve ter os seguintes atributos de textura suave e sem fissuras e corpo viscoso, firme e coeso para ser consumido com colher. A Figura 5 mostra a textura de iogurte preparado com misturas de bactérias lácticas após um e sete dias de armazenamento a $4{ }^{\circ} \mathrm{C}$. Após um dia, a consistência medida pela força de penetração de um cilindro de $2,5 \mathrm{~cm}$ de diâmetro em analisador de textura TAXT2 variou de 70,1 a 86,0 g, para iogurtes contendo probióticos segundo a composição da co-cultura empregada. Esta consistência é similar à do produto fabricado com as culturas clássicas do iogurte usado como controle. Observa-se que após sete dias de armazenamento a força aumentou para 77,8 a 92,1 g, evidenciando ganho de consistência como resultado da formação da estrutura do produto.

\section{Estabilidade e viabilidade}

Diversos fatores afetam a viabilidade dos microrganismos probióticos em produtos lácteos fermentados, entre eles a cepa, a pós-acidificação, a composição da co-cultura e a presença de fatores de crescimento no leite (Gilliliand, Speck, 1977; Klaver et al., 1993; Samona, Robinson, 1994; Rybka, Kailasapathy, 1995; Lankaputhra, Shah, 1996; Lankaputhra et al., 1996; Shah, Lankaputhra, 1997; Vinderola et al., 2000a, b ; Shah, 2000).

Estudos anteriores indicaram que diversos fatores podem influenciar a sobrevivência de L. acidophilus durante a estocagem. Entre estes, encontram-se a cepa utilizada (Gilliland, 1979; Gilliland, Lara, 1988), o meio de cultura utilizado na produção de células, o valor de $\mathrm{pH}$ no qual as células são propagadas e a fase na qual os lactobacilos são colhidos (Brashears, Gilliland, 1995).

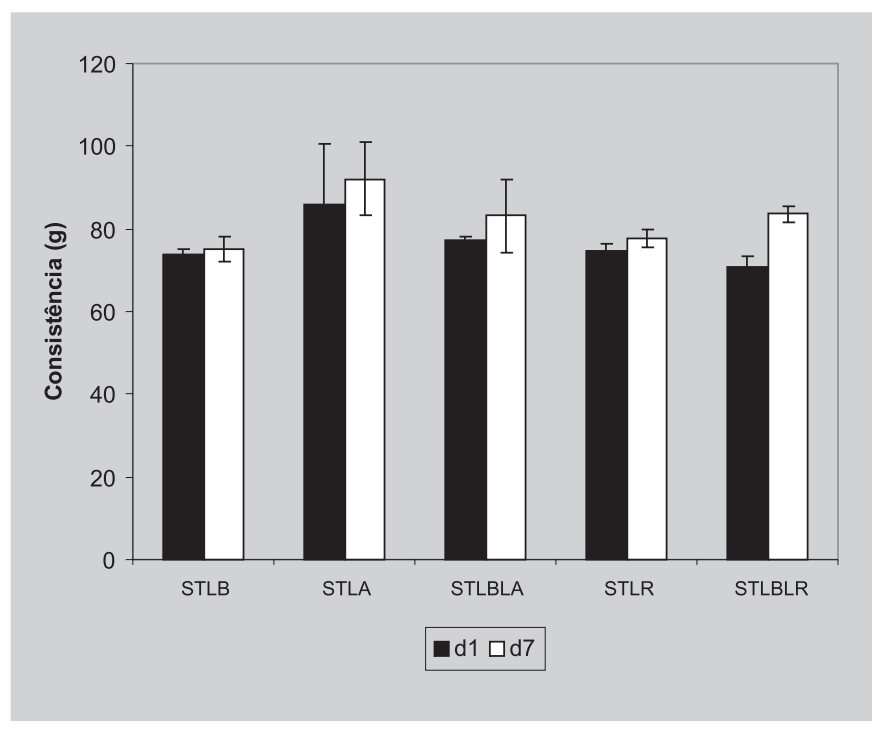

FIGURA 5 - Textura de iogurtes preparados com culturas mistas de probióticos após um dia (d1) e 7 dias (d7) de conservação a $4{ }^{\circ} \mathrm{C}$. (STLB: $0,250 \%$ S. thermophilus + $0,250 \%$ L. bulgaricus; STLA: 0,250\% $S$ thermophilus + $0,250 \%$ L. acidophilus; STLBLA: $0,125 \%$ Str. thermophilus $+0,125 \%$ L. bulgaricus $+0,250 \% \mathrm{~L}$. acidophilus; STLR: 0,250\% Str. thermophilus $+0,250 \% \mathrm{~L}$. rhamnosus; STLBLR: 0,125\% S. thermophilus $+0,125 \%$ L. bulgaricus $+0,250 \%$ L. rhamnosus ). Dados originais obtidos de acordo com metodologia descrita em Oliveira et al., 2001.

Baixos valores de $\mathrm{pH}$ inibem o metabolismo e, conseqüentemente, o crescimento de L. acidophilus e são nocivos para as células bacterianas, reduzindo sua viabilidade.

Na Figura 6 é apresentada a viabilidade de bactérias probióticas em bebidas lácteas ao longo do armazenamento a $4{ }^{\circ} \mathrm{C}$. No início, as contagens de L. bulgaricus, $L$. acidophilus e L. rhamnosus foram $2,4 \times 10^{8} \mathrm{UFC} / \mathrm{mL}, 1,7$ x $10^{8} \mathrm{UFC} / \mathrm{mL}$ e $4,1 \times 10^{7} \mathrm{UFC} / \mathrm{mL}$, respectivamente. Após 14 dias de armazenagem as contagens permaneceram estáveis. Pode-se observar que a armazenagem afeta a concentração de lactobacilos apenas após 21 dias a $4{ }^{\circ} \mathrm{C}$. Esta diminuição é mais pronunciada no caso do L. acidophilus do que com L. bulgaricus e com L. rhamnosus. Após 28 dias, as contagens de bactérias probióticas diminuiram 1,41 unidades $\log$ para $L$. bulgaricus, 1,74 unidades log para o $L$. acidophilus e 1,1 unidades log para o L. rhamnosus (Figura 6).

Foschino et al. (1997) estudaram os efeitos das taxas de refrigeração e de armazenamento sobre a viabilidade e atividade fermentativa de culturas puras de L. acidophilus em um período de 9 meses. Altas taxas de sobrevivência e 
maior atividade foram observadas armazenando as culturas a $-80{ }^{\circ} \mathrm{C}$, mas diversas culturas estocadas a $-30{ }^{\circ} \mathrm{C}$ também sobreviveram bem. A análise de variância mostrou que a viabilidade de culturas congeladas é mais afetada pela temperatura de armazenamento que pela taxa de refrigeração.

Segundo Brashears, Gilliland (1995), um veículo de L. acidophilus provém de um produto lácteo não fermentado. Este produto é preparado com a adição de células de uma cultura concentrada congelada ao leite magro pasteurizado e após armazenamento do leite em temperatura de refrigeração. Cuidados são necessários visando à obtenção de número adequado de lactobacilos, pois as células devem sobreviver congeladas e subseqüentemente às condições de refrigeração.

Kailasapathy e Supriadi (1996) observaram que número de $L$. acidophilus permaneceu viável durante a estocagem de iogurtes preparados com a adição de $\beta$ galactosidase ao leite e proteína concentrada de soro durante armazenamento a $5^{\circ} \mathrm{C}$, durante 3 semanas.

A determinação do efeito da refrigeração sobre a viabilidade de cinco cepas de L. acidophilus e uma de $L$. casei em leitelho e iogurte foi conduzida por Nighswonger et al. (1996). As cepas de L. acidophilus MUH-41, O-16 e L-1 em leitelho, a $5{ }^{\circ} \mathrm{C}$, não perderam sua viabilidade enquanto a 43121 e a La-5 perderam sua viabilidade. Em iogurte, a $7{ }^{\circ} \mathrm{C}$, MUH-41 e L-1 não apresentaram perda significativa da viabilidade. Não foi observada perda de viabilidade do $L$. casei durante a estocagem de todos os produtos.

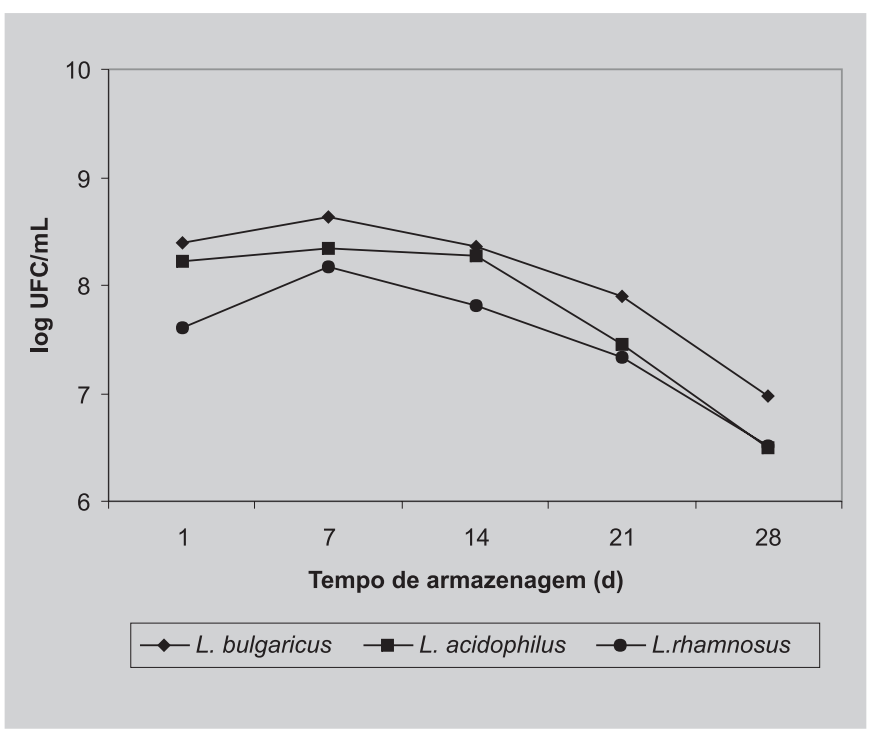

FIGURA 6 - Viabilidade de bactérias probióticas em bebidas lácteas ao longo do armazenamento a $4{ }^{\circ} \mathrm{C}$. FONTE: Oliveira et al., 2002 (no prelo).
Roushdy et al. (1996) prepararam leitelho a partir de leite de búfala contendo acidófilos e bífidobactéria misturando com culturas normais em diferentes proporções. A acidez e o teor de acetaldeído foram maiores em leite contendo acidófilos e bifidus que com as culturas normais, mesmo ao longo da estocagem. A contagem de $L$. acidophilus, B. bifidum e culturas mesofílicas aumentaram durante os três primeiros dias de estocagem diminuindo a seguir.

Kailasapathy e Rybka (1997) relataram que a sobrevivência de L. acidophilus e Bifidobacterium spp. depende de diversos fatores intrínsecos e extrínsecos, como o meio, o tempo e a temperatura de fermentação, o nível de oxigênio no meio, o tipo de bactéria empregada e o valor de $\mathrm{pH}$ final.

Rybka e Fleet (1997) examinaram quinze iogurtes de 16 fabricantes australianos contendo probióticos $L$. acidophilus e Bifidobacterium spp. As populações viáveis de L. bulgaricus e Str. thermophilus excederam $10^{7} \mathrm{UFC} / \mathrm{mL}$ em $54 \%$ e $68 \%$ das amostras, respectivamente. Apenas 24 e $14 \%$ das amostras contendo L. acidophilus e Bifidobacterium spp., respectivamente, excederam $10^{6} \mathrm{UFC} / \mathrm{mL}$. Iogurtes mais ácidos são aqueles contendo maiores populações de L. bulgaricus e níveis de $10^{6} \mathrm{UFC} / \mathrm{g}$ de L. acidophilus e B. spp.

Dave e Shah (1997b) estudaram a viabilidade de bactérias do iogurte e de bactérias probióticas durante a fabricação e armazenamento por 35 dias de iogurtes suplementados com ácido ascórbico em quatro níveis, empregando culturas comerciais. A contagem de $L$. acidophilus durante a estocagem decresceu mais lentamente com o aumento da concentração de ácido ascórbico para todas as culturas estudadas, enquanto a contagem de bifidobactéria permaneceu inalterada.

Foschino et al. (1997) estudaram 43 amostras de leites fermentados com bactérias probióticas (L. acidophilus e/ou Bifidobacterium) de diferentes marcas durante a vida de prateleira a $4{ }^{\circ} \mathrm{C}$. Dois de seis leites fermentados mantiveram as contagens bacterianas acima de $10^{6} \mathrm{UFC} / \mathrm{g}$ até o final do prazo de validade. Bifidobacterium não foi encontrado mesmo em pequenas concentrações e próximo à data de fabricação em um dos produtos estudados. Em dois produtos, as espécies isoladas não foram aquelas correspondentes às declaradas no rótulo. Amostras de diferentes lotes pertencentes à mesma marca mostraram grandes diferenças na concentração de microrganismos. Leites fermentados naturais e adicionados de frutas, inteiros e de baixo conteúdo em gordura, de quatro marcas comerciais australianas foram estudados. Os produtos eram fabricados com S. thermophilus, L. bulgaricus, L. acidophilus e Bifidobacterium spp. durante a vida de prateleira a 4 e a 
$10{ }^{\circ} \mathrm{C}$. Os autores concluíram que os produtos mantinham as bactérias viáveis até seis semanas de armazenamento a $4{ }^{\circ} \mathrm{C}$. A temperatura de $10^{\circ} \mathrm{C}$ exerceu pouca influência sobre as culturas e a presença de gordura não afetou a viabilidade (Micanel et al., 1997).

Shah e Lankaputhra (1997) estudaram a viabilidade de bactérias probióticas em leites fermentados utilizando células rompidas e inteiras de L. bulgaricus 2515 e $S$. thermophilus 2010 e células inteiras de bactérias probióticas L. acidophilus 2409, e uma espécie de Bifidobacterium; B. longun 1941, B. infantis 1912, B. bifidum 1900. Contagens de bactérias probióticas viáveis após fermentação foram dois ciclos log mais altas em iogurte preparado com bactérias rompidas do iogurte e células inteiras de bactérias probióticas. A viabilidade das bactérias probióticas após seis semanas foi superior a recomendação de $10^{6} \mathrm{UFC} / \mathrm{g}$.

Bolin et al. (1998) estudando diferentes cepas de $L b$. acidophilus (B, V-74, CH-2 e CH-5) verificaram que o número de células viáveis a $\mathrm{pH} 2,5$ variou de $5,1 \mathrm{x}$ $10^{8} \mathrm{UFC} / \mathrm{mL}$ a $10 \times 10^{8} \mathrm{UFC} / \mathrm{mL}$ antes da incubação a $37^{\circ} \mathrm{C}$. Após $6 \mathrm{~h}$ de incubação, forma detectadas 2-2,6 x $10^{6} \mathrm{UFC} / \mathrm{mL}$ de células viáveis. A tolerância ao baixo valor de $\mathrm{pH}$ foi bastante variável e dependeu da cepa: $\mathrm{B}$ e V-74 mostaram-se mais tolerantes que $\mathrm{CH}-2 ; L$. acidophilus $\mathrm{CH}-5$ exibiu a menor sobrevivência a pH 2,5 após $6 \mathrm{~h}$ de incubação.

Aumento da acidez do produto durante a estocagem afeta a viabilidade das bactérias probióticas. Bifidobactérias não são ácido loterantes como o L. acidophilus; o crescimento deste último cessa em valores de $\mathrm{pH}$ inferiores a 4,0 enquanto o crescimento de Bifidobacterium spp. é retardado em pH 5,0 (Shah, 1997).

Peróxido de hidrogênio produzido por alguns lactobacilos tem atividade antimicrobiana. Bifidobactérias são anaeróbicas por natureza. Assim, altas concentrações de oxigênio afetam seu crescimento e sua viabilidade. A composição do produto, a presença de conservadores como resultado da adição de frutas e nozes e a disponibilidade de fatores de crescimento também afetam o crescimento e viabilidade de bactérias do iogurte e as probióticas (Dave, Shah, 1998).

Lorca et al. (1998) avaliaram a resposta do $L b$. acidophilus ao estresse quando em ambientes ácidos, evidenciando que a sensibilidade depende da fase de crescimento. Células da cultura na fase estacionária são tolerantes ao valor de $\mathrm{pH} 3,0$, mas, esta resistência é perdida quando na fase exponencial. Com o declínio do valor de $\mathrm{pH}$, as células retomam a resistência ao meio ácido e a capacidade de sobrevivência aumenta até $4 \mathrm{~h}$ de incubação, mantendo-se constante a seguir.
Dave e Shah (1998) estudaram a viabilidade de Streptococus thermophilus, L. acidophilus e bifidobactéria em leites fermentados adicionados de cisteína, soro em pó, proteína concentrada de soro, hidrolisados ácidos de caseína e triptona. A viabilidade de $S$. thermophilus foi contrariamente afetada enquanto a de L. acidophilus mantida com a adição de cisteína. As contagens de $L$. acidophilus mantiveram-se superiores a $10^{5} \mathrm{UFC} / \mathrm{mL}$ durante os 35 dias de estocagem do produto. Uma redução de três ciclos logarítmicos na contagem das bifidobactérias foi observada quando o valor de $\mathrm{pH}$ atingiu 4,5 no iogurte controle e naquele suplementado com soro em pó.

Nogueira et al. (1998), analisando a qualidade microbiológica de iogurtes portugueses durante a vida de prateleira, constataram que embora a flora específica decline durante o armazenamento, os iogurtes apresentaram um número de microrganismos probióticos de acordo com o recomendado.

Patidar e Prajapati (1998) prepararam "lassi” usando leite padronizado e L. acidophilus e Str. thermophilus. A contagem de estreptococos e de lactobacilos no produto fresco foi de $15,85 \times 10^{6} \mathrm{UFC} / \mathrm{g}$ e $20,4 \times 10^{7} \mathrm{UFC} / \mathrm{g}$, respectivamente. Estas permaneceram inalteradas durante a estocagem por 15 dias a $7{ }^{\circ} \mathrm{C}$ e não foram afetadas pelo tipo de embalagem.

Tejada-Simon et al. (1999), estudando o efeito da ingestão de iogurte contendo L. acidophilus e Bifidobacterium na potenciação da imunoglobulina A verificaram que a viabilidade das bactérias lácteas e bifidobactéria permaneceu acima de $10^{6} \mathrm{UFC} / \mathrm{mL}$ no produto refrigerado e armazenado durante quatro semanas.

Gardini et al. (1999), utilizando Desenho Composto Central, apontaram o efeito das variáveis gordura, sólidos lácteos não gordurosos e tamanho do inóculo de $L$. acidophilus sobre a viabilidade microbiológica de $L$. bulgaricus, Str. thermophilus e L. acidophilus e, também a característica de flavor de leites fermentados durante armazenamento a $4{ }^{\circ} \mathrm{C}$. Os modelos polinomiais obtidos permitiram individualizar os níveis das três variáveis independentes capazes de minimizar a perda de viabilidade das bactérias. Foi possível, ainda, definir os efeitos destas variáveis sobre o perfil de aroma. Os resultados da análise sensorial confirmaram que as características organolépticas dos produtos não foram afetadas pelo tamanho do inóculo de L. acidophilus, mas somente pelo teor de sólidos e de gordura.

A influência da atividade de água em função da adição de açúcar no tempo de acidificação e na viabilidade das bactérias do iogurte e das probióticas foram investigadas por Shah e Ravula (2000). Os autores conclu- 
íram que a adição de açúcar pode ser deletéria ao crescimento dos microrganismos, especialmente em produtos como sobremesas lácteas congeladas contendo cerca de $16 \%$ de açúcar.

\section{Desempenho tecnológico em outros produtos}

Gardiner et al. (1999) alegaram que, embora muita pesquisa em termos de probióticos se encontre voltada para produtos como leites fermentados e iogurtes, esses produtos podem não ser ótimos no que diz respeito à manutenção de altas concentrações de algumas cepas. Aliado a esse fato, há evidências de que outros alimentos oferecem potencial para a administração dessas culturas. Como exemplo pode ser citado o leite de soja fermentado (Svensson 1999), o sorvete de iogurte (Davidson et al., 2000) e os produtos nutritivos em pó (Ingham, 1999).

Diversos tipos de queijo foram testados como veículos para cepas probióticas de Lactobacillus e de Bifidobacterium, revelando-se apropriados. Dentre os queijos testados para esse fim, destacam-se os queijos Cheddar (Dinakar, Mistry, 1994; Gardiner et al., 1998), Gouda (Gomes et al., 1998), Cottage (Blanchette et al., 1996), Crescenza (Gobbetti et al., 1997) e queijo fresco (Roy et al., 1997; Vinderola et al., 2000c).

Em estudo com queijo tipo Cheddar, utilizando a cepa probiótica Enterococcus faecium, Gardiner et al. (1999) relataram que esse queijo demonstrou melhor capacidade tamponante, oferecendo melhor proteção à cultura probiótica no que diz respeito à exposição ao suco gástrico, quando comparado ao iogurte. Os autores concluíram que o queijo Cheddar é tão ou mais eficiente que o iogurte como veículo de microrganismos probióticos viáveis no trato gastrintestinal de suínos, mesmo após 15 meses de fabricação.

Daigle et al. (1999) relataram um estudo com queijo semelhante ao Cheddar produzido com leite microfiltrado. O leite era padronizado por meio da adição de creme enriquecido com retentato de fosfocaseinato e fermentado com Bifidobacterium infantis (concentração inicial de $10^{7}$ e $10^{8} \mathrm{UFC} / \mathrm{g}$ de creme). Os autores obtiveram contagens de bifidobactéria em níveis acima de $10^{6} \mathrm{UFC} / \mathrm{g}$ durante, pelo menos, 12 semanas. Paralelamente, não foram observados efeitos da cultura sobre as características organolépticas dos queijos.

Gomes e Malcata (1999) relataram que o processamento de queijo de leite de cabra com adição das culturas probióticas Bifidobacterium lactis e L. acidophilus pode ser empregado para a obtenção de um queijo com boas características de sabor e textura. Os autores observaram que a sobrevivência das cepas probióticas mostrou- se dependente das características físico-químicas do queijo, mas que as contagens finais desses microrganismos revelaram-se acima do limiar aceitável para o efeito probiótico $\left(10^{6} \mathrm{UFC} / \mathrm{g}\right)$.

Stanton et al. (1998) salientaram que um alimento como o queijo Cheddar só poderá ser considerado funcional se a cultura probiótica adicionada durante o seu processamento resistir à sua maturação e não prejudicar sua composição, sua textura e suas características sensoriais.

Vinderola et al. (2000b) concluíram favoravelmente sobre a possibilidade de usar queijo fresco argentino como veículo de probióticos usando B. bifidum (duas cepas), Bifidum sp. (uma cepa), L. acidophilus (duas cepas) e $L$. casei (duas cepas) em diferentes combinações.

Em estudos realizados com queijo Minas frescal fabricado com $1 \%$ de cultura probiótica composta por $S$. thermophilus, B. lactis e L. acidophilus e mantido armazenado durante 21 dias a $8,5^{\circ} \mathrm{C}$, a viabilidade do $L$. acidophilus permaneceu estável nos 14 primeiros dias, aumentando ligeiramente para após 21 dias. A contagem de probióticos foi de $1,3 \times 10^{6}$ a 3,4 × $10^{7} \mathrm{UFC} / \mathrm{g}$, enquanto a de $S$. thermophilus variou de $3,8 \times 10^{8}$ a $8,0 \times 10^{8} \mathrm{UFC} / \mathrm{g}$ (Figura 7). Na Figura 8 são comparadas as texturas de queijos fabricados com $1 \%$ de culturas probióticas $(S$. thermophilus, B. lactis e L. acidophilus) e com $1 \%$ da cultura clássica tipo $\mathrm{O}$ (L. lactis + L. cremoris) e com $2 \mathrm{~mL}$ de ácido lático a 85\%/10 L de leite após um dia (d1) e 7 dias (d7) de conservação a $8,5^{\circ} \mathrm{C}$. Observa-se que a textura do queijo fabricado com culturas probióticas após um dia da fabricação apresenta dureza intermediária entre a dos queijos fabricados com a cultura $\mathrm{O}$ e com ácido lático. Após 7 dias, a dureza do queijo preparado com cultura probiótica aumenta provavelmente devido à pósacidificação e perda de umidade.

A aplicação de culturas probióticas em produtos que não são derivados do leite representa mudança. A viabilidade de probióticos na matriz de alimentos depende de muitos fatores, tais como, $\mathrm{pH}$, temperatura da estocagem, presença de microrganismos competidores e inibidores. Em produtos como alimentos infantis é importante que a atividade e viabilidade da cultura probiótica se estenda por um período de tempo. Fatores como atividade de água, tensão do oxigênio e temperatura são muito importantes neste tipo de produto. A temperatura da sala de estocagem, que é muito alta em produtos de cereais e bebidas pode afetar a estabilidade do probiótico. Este problema pode ser resolvido utilizando-se cultura probiótica encapsulada (Saarela et al., 2000). Alimentos infantis contendo probióticos têm sido desenvolvidos e comercializados (Langhendries et al., 1995). 


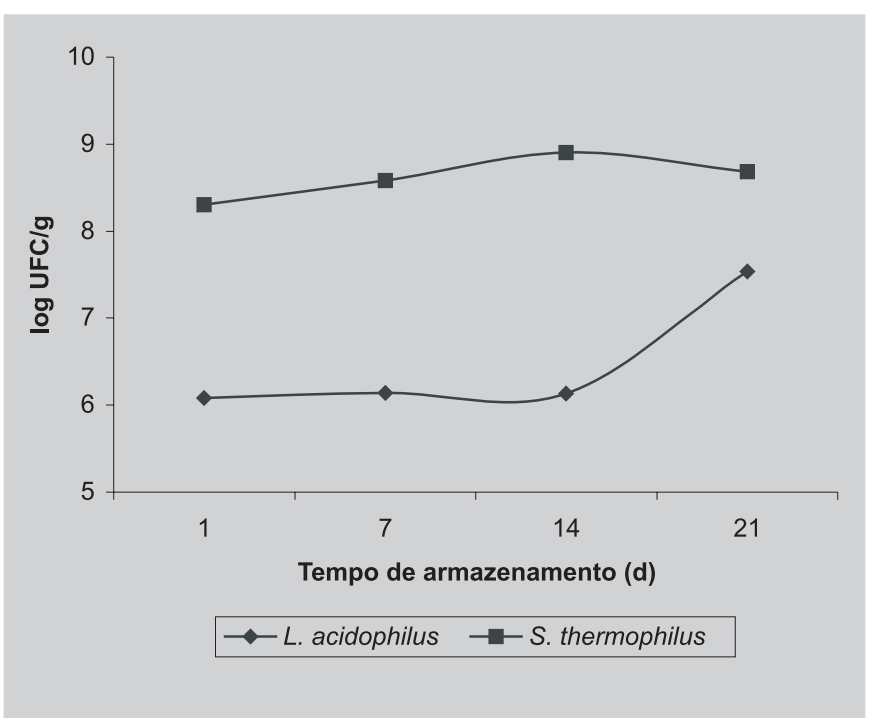

FIGURA 7 - Viabilidade de bactérias probióticas em queijo Minas frescal ao longo do armazenamento a $8,5^{\circ} \mathrm{C}$. Dados originais obtidos segundo metodologia descrita em Oliveira et al., 1996 e Okazaki et al., 2001.

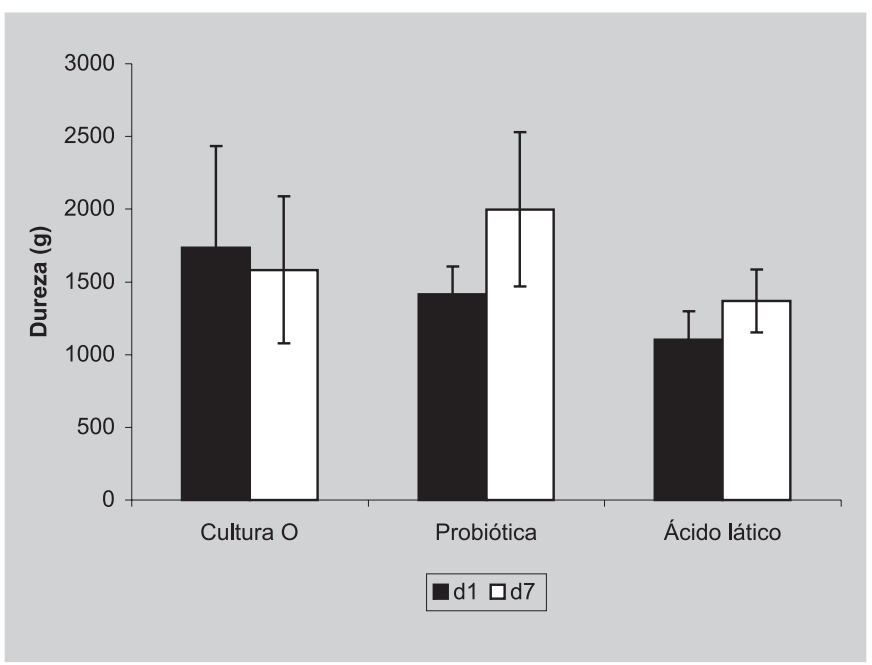

FIGURA 8 - Textura de queijos Minas frescal preparados com cultura O (L. Lactis + L. cremoris), probiótica (Str. thermophilus + B. lactis + L. acidophilus) e ácido lático após um dia (d1) e 7 dias (d7) de conservação a $8,5^{\circ} \mathrm{C}$. Dados originais obtidos segundo metodologia descrita Oliveira et al., 1996 e Buriti et al., 2001.

\section{PRINCIPAIS PRODUTOS CONTENDO PROBIÓTICOS}

No Mercado Europeu observa-se crescimento no desenvolvimento de produtos lácteos fermentados e funcionais, refletindo grande interesse no estudo de alimentos que demonstrem benefícios à saúde. Atualmente, estima-se que cerca de $13 \%$ do total de iogurtes vendidos na Europa contenham probióticos (Daly et al, 1998). Estima-se que este mercado perfaça total de 889 milhões de dólares, sendo que o mercado francês é considerado como o maior, atingindo cerca de 219 milhões de dólares (Stanton et al., 2001).

Para este fim, diversos fabricantes desenvolveram e licenciaram suas próprias bactérias probióticas como Lactobacillus johnsonii (Nestlé), Lactobacillus GG (Valio), LA7 (Bauer), Causido (MD Foods) e Lacticel (Danone). Também, leite fermentado de origem japonesa contendo Lb. casei, Shirota (Yakult) ganha mercado tanto na Europa quanto no Reino Unido (Daly et al., 1998). Segundo Sanders (1999) o mercado de probióticos nos Estados Unidos é pouco desenvolvido e de difícil acesso.

No Brasil, estima-se consumo de leites fermentados contendo probióticos como em torno de $120 \mathrm{mil}$ ton/ano (Food Ingredients, 2000). São encontrados no mercado brasileiro alguns produtos alimentícios contendo probióticos, como leite fermentado aromatizado ou não, e iogurte. A relação com a categoria e o nome do produto, o produtor, as bactérias e as funções atribuídas são mostrados na Tabela IV. Dentre os produtos considerados como farmacêuticos comercializados no Brasil podem ser citados alguns na forma de suplemento alimentar, suspensão oral e comprimidos como contendo probióticos (Tabela V).

\section{CONCLUSÕES}

Apesar dos diversos estudos clínicos realizados não terem conseguido provar definitivamente a eficácia desses microrganismos sobre a saúde, sabe-se que os mesmos exercem influências significativas sobre sintomas clínicos de determinadas doenças como a alergia alimentar infantil. Estudos clínicos demonstraram que as cepas consideradas probióticas são capazes de sobreviver ao processo digestivo, sendo algumas delas capazes de aderir à mucosa intestinal. Foi observado que a ingestão de probióticos resulta em melhoria da qualidade de vida de indivíduos com doenças crônicas mediadas pelo sistema imunológico, como as doenças inflamatórias intestinais (doença de Crohn e colite ulcerativa).

O campo para o desenvolvimento de tecnologias envolvendo o emprego de culturas probióticas é deveras promissor e requer inúmeros estudos, a fim de que se possa estabelecer definitivamente o mecanismo de ação dessas culturas e os veículos apropriados para que essas culturas atinjam o intestino em concentrações efetivas e de maneira a exercer o seu efeito apropriadamente. Em geral, pode-se dizer que o processamento de alimentos funcionais contendo bactérias probióticas, principalmente sua 
TABELA IV - Principais produtos alimentícios contendo bactérias probióticas comercializados no Brasil

\begin{tabular}{|c|c|c|c|c|}
\hline Categoria do produto & Produto & Produtor & Probióticos & Funções atribuidas \\
\hline \multirow[t]{4}{*}{ Leite fermentado } & Yakult & Yakult & $\begin{array}{l}\text { L. casei cepa } \\
\text { Shirota }\end{array}$ & $\begin{array}{l}\text { Normalizar o equilíbrio da } \\
\text { microbiota intestinal } \\
\text { humana }\end{array}$ \\
\hline & Chamyto & Nestlé & $\begin{array}{l}\text { L.johnsonii } \\
\text { L. helveticus }\end{array}$ & 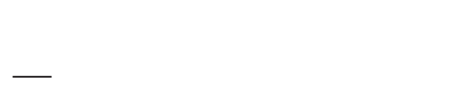 \\
\hline & $\begin{array}{l}\text { Leite Fermentado } \\
\text { Parmalat }\end{array}$ & Parmalat & $\begin{array}{l}\text { L.casei } \\
\text { B.lactis } \\
\text { L. acidophilus }\end{array}$ & - \\
\hline & $\begin{array}{l}\text { Vigor Club - } \\
\text { Poke-mons }\end{array}$ & Vigor & $\begin{array}{l}\text { L.casei } \\
\text { L. acidophilus }\end{array}$ & - \\
\hline \multirow{2}{*}{$\begin{array}{l}\text { Leite fermentado } \\
\text { aromatizado }\end{array}$} & Batavito & Batavo & L. casei & - \\
\hline & $\begin{array}{l}\text { LC1 Active } \\
\text { (sabor laranja) }\end{array}$ & Nestlé & $\begin{array}{l}\text { S.thermophilus } \\
\text { L. bulgaricus } \\
\text { L. acidophilus NCC } 208\end{array}$ & $\begin{array}{l}\text { Prevenir a instalação de } \\
\text { bactérias nocivas na parede } \\
\text { do intestino; estimular as } \\
\text { células do sistema } \\
\text { imunológico, aumentando os } \\
\text { anticorpos }\end{array}$ \\
\hline \multirow[t]{2}{*}{ Iogurte } & Iogurte Biofibras & Batavo & $\begin{array}{l}\text { B. lactis } \\
\text { L. acidophilus }\end{array}$ & \\
\hline & Dietalact & Parmalat & $\begin{array}{l}\text { B. lactis } \\
\text { L acidophilus }\end{array}$ & - \\
\hline
\end{tabular}

TABELA V - Principais produtos farmacêuticos contendo bactérias probióticas comercializados no Brasil

\begin{tabular}{|c|c|c|c|c|}
\hline Categoria do produto & Produto & Produtor & Probióticos & Funções atribuidas \\
\hline $\begin{array}{l}\text { Suplemento alimentar } \\
\text { Envelopes de } 3 \mathrm{~g} \text { para } \\
\text { misturar com } \\
\text { bebidas frias }\end{array}$ & Biotura & Chr. Hansen & $\begin{array}{l}\text { L. acidophilus } \\
\text { B. lactis } 10^{9} \mathrm{UFC}\end{array}$ & $\begin{array}{l}\text { Manter a flora intestinal em } \\
\text { equilíbrio }\end{array}$ \\
\hline Suspensão oral* & Leiba & $\begin{array}{l}\text { União Química- } \\
\text { Farmacêutica } \\
\text { Nacional }\end{array}$ & $\begin{array}{l}\text { L. acidophilus } \\
2,0 \times 10^{8} \mathrm{UFC}\end{array}$ & $\begin{array}{l}\text { Normalizar o equilíbrio da } \\
\text { microbiota intestinal }\end{array}$ \\
\hline Comprimidos & Floratil & Merck & Saccharomyces buoladii & $\begin{array}{l}\text { Normalizar o equilíbrio da } \\
\text { microbiota intestinal }\end{array}$ \\
\hline
\end{tabular}

\footnotetext{
* forma farmacêutica cuja fórmula e apresentação encontram-se em reformulação
} 
incorporação em leites fermentados e queijos, vem resultando em produtos com alto grau de aceitabilidade, nos quais a sua viabilidade e funcionalidade são mantidas.

\section{ABSTRACT}

\section{Technological aspects of functional foods containing probiotics}

Functional food science is being considered priority of research nowadays and studies are directed towards attempts to elucidate their proprieties and effects in promoting health. Probiotics are viable microbial dietary supplements that have beneficial effects over the health of the host by means of modulation of the intestinal microflora. Some beneficial properties attributed to probiotic microorganisms still need more controlled studies to be definitely established. This article deals with technology aspects related to probiotics, the effects associated with the consumption of food products containing these microorganisms and the main strains employed for that purpose. Experimental data are also presented in order to illustrate technological aspects of the manufacture of food products containing probiotics, intending to describe their limitations and alternatives.

UNITERMS: Functional foods. Probiotics. Nutraceutical. Lactobacillus spp. Bifidobacterium spp.

\section{AGRADECIMENTOS}

Os autores agradecem à FAPESP pelo apoio financeiro aos Projetos 99/08332-2, 00/03803-7, 00/01978-4, 00/14680-3, 00/14681-0, 00/14679-5 e 01/02389-5 e ao CNPq.

\section{REFERÊNCIAS BIBLIOGRÁFICAS}

ARUNACHALAM, K. Role of bifidobacteria in nutrition, medicine and technology. Nutr. Res., Amsterdam, v.19, n.10, p.1559-1597, 1999.

BLANCHETTE, L., ROY, D., BELANGER, G., GAUTHIER, S.F. Production of cottage cheese using dressing fermented by bifidobacteria. J. Dairy Sci., Savoy, v.79, p.8-15, 1996.

BOLIN, Z., LIBUDZISZ, Z., MONETA, J. Selection of Lactobacillus acidophilus strains for use as dietary adjuncts in cultured dairy products. Polish J. Food Nutr. Sci., Olsztyn, v.7, n.1, p. 107-116, 1998.
BOTTAZZI, V., BATTISTOTTI, B., MONTESCANI, G. Influence of single and associated strains of $L$. bulgaricus and $S$. thermophilus as well as milk treatments on the production of acetaldehyde in yoghurt. Lait, Les Ulis, v.53, p.295-308, 1973.

BRASHERS, M.M., GILLILAND, S.E. Survival during frozen and subsequent refrigerated storage of Lactobacillus acidophilus cells as influenced by the growth phase. J. Dairy Sci., Savoy, v.78, p.2326-2335. 1995.

BRASIL. Portaria n ${ }^{\circ} 15$, de 30 de abril de 1999. Institui, junto à Câmara Técnica de Alimentos, comissão de assessoramento de alimentos funcionais enovos alimentos. Diário Oficial da União, Brasília, 14 maio 1999. Seção 2. 1999a.

BRASIL. Resolução nº 16, de 30 de abril de 1999. Regulamento técnico de procedimentos para registro de alimentos e ou novos ingredientes Diário Oficial da União, Brasília, 3 dez. 1999. 1999 b.

BRASIL. Resolução n ${ }^{\circ} 18$, de 30 de abril de 1999. Regulamento técnico que estabelece as diretrizes básicas para análise e comprovação de propriedades funcionais e ou de saúde alegadas em rotulagem de alimentos. Diário Oficial da União, Brasília, 3 mai. 1999. Seção 1, p.11. 1999c.

BRASIL. Resolução n 19 , de 30 de abril de 1999. Regulamento técnico de procedimentos para registro de alimento com alegação de propriedades funcionais e ou de saúde em sua rotulagem. Diário Oficial da União, Brasília, 3 mai. 1999. Seção 1, p.11. 1999d.

BURITI, F.C.A., ALEGRO, J.H.A., SAAD, S.M.I. Perfil de textura e avaliação sensorial de queijo Minas frescal processado com a adição de uma co-cultura probiótica. Rev. Bras. Ciências Farmacêuticas, São Paulo, v.37, supl.1, p.41, 2001. Res. ALN41. [Semana de Ciência e Tecnologia da Faculdade de Ciências Farmacêuticas da Universidade de São Paulo, 6, São Paulo, 2001].

COLLINS, J.K., THORNTON, G., SULLIVAN, G.O. Selection of probiotic strains for human applications. Int. Dairy J., Amsterdam, v.8, p.487-490, 1998.

DAIGLE, A., ROY, D., BÉLANGER, G., VUILLEMARD, J.C. Production of probiotic cheese (Cheddar-like cheese) using enriched cream fermented by Bifidobacterium infantis. J. Dairy Sci., Savoy, v.82, n.6, p.1081-1091, 1999. 
DALY, C., GERALD, F.F., O'CONNOR, L., DAVIS, R. Technological and health benefits of dairy starter cultures. Int. Dairy J., Amsterdam, v.8, p.195-205, 1998.

DAVE, R.I., SHAH, N.P. Effectiveness of ascorbic acid as an oxygen scavenger in improving viability of probiotic bacteria in yoghurts made with commercial starter cultures. Int. Dairy J., Amsterdam, v.7, p.435-443, 1997a.

DAVE, R.I., SHAH, N.P. Viability of yoghurt and probiotic bacteria in yoghurts made from commercial starter cultures. Int. Dairy J., Amsterdam, v.7, p.31-41, 1997 b.

DAVE, R.I., SHAH, N.P. Ingredient supplementation effects on viability of probiotic bacteria in yogurt. J. Dairy Sci., Savoy, v.81, p.2804-2816, 1998.

DAVIDSON, R.H., DUNCAN, S.E., HACKNEY, C.R., EIGEL, W.N., BOLING, J.W. Probiotic culture survival and implications in fermented frozen yogurt characteristics. J. Dairy Sci., Savoy, v.83, n.4, p.666-673, 2000 .

DINAKAR, P., MISTRY, V.V. Growth and viability of Bifidobacterium bifidum in cheddar cheese. J. Dairy Sci., Savoy, v.77, n.10, p.2854-2864, 1994.

DU PLESSIS, E.M., DICKS, L.M.T., VESCOVO, M., TORRIANI, S., DELLAGLIO, F. Lactobacillus acidophilus and related species: a review. Ann. Microbiol. Enzimol., Milan, v.46, p.319-340, 1996.

FOOD INGREDIENTS. Leites fermentados com probióticos contribuem para uma vida mais saudável. São Paulo: Fonte Comunicações e Editora Ltda., mai/jun, n.6, p.40-46, 2000.

FOSCHINO, R., CAFARO, I., OTTOGALLI, G. Studio sulla vitalità di batteri «probiotici» presenti in campioni di latti fermentati del commercio. Ann. Microbiol. Enzimol., Milan, v.47, p.151-164, 1997.

FULLER, R. Probiotics in man and animals. J. Appl. Bacteriol., Oxford, v.66, p.365-378, 1989.

FULLER, R. History and development of probiotics. New York: Marcell Dekker, 1994. p.1-8.
GARDINER, G., ROSS, R.P., COLLINS, J.K., FITZGERALD, G., STANTON, C. Development of a probiotic cheddar cheese containing human-derived Lactobacillus paracasei strains. Appl. Environ. Microbiol., Washington, v.64, p.2192-2199, 1998.

GARDINER, G., STANTON, C., LYNCH, P.B., COLLINS, J.K., FITZGERALD, G, ROSS, R.P. Evaluation of cheddar cheese as a food carrier for delivery of a probiotic strain to the gastrointestinal tract. J. Dairy Sci., Savoy, v.82, n.7, p.1379-1387, 1999.

GARDINI, F., LANCIOTTI, R., GUERZONI, M.E., TORRIANI, S. Evaluation of aroma production and survival of Streptococcus thermophilus, Lactobacillus delbrueckii subsp. bulgaricus and Lactobacillus acidophilus in fermented milks. Int. Dairy J., Amsterdam, v.9, p.125-134, 1999.

GILLILAND, S.E. Beneficial interrelationships between certain microrganisms and humans: candidate microrganisms for use as dietary adjunts. J. Food Prot., Des Moines, v.42, p.164-168, 1979.

GILLILAND, S.E. Acidophilus milk products. A review of potential benefits to consumers. J. Dairy Sci., Savoy, v.72, p.2483-2494, 1989.

GILLILAND, S.E., LARA, R.C. Influence of storage at freezing and subsequent refrigeration temperatures on bgalactosidase activity of Lactobacillus acidophilus. Appl. Environ. Microbiol., Washington, v.54, p.898-902, 1988.

GILLILAND, S.E., SPECK, M.L. Instability of Lactobacilus acidophilus in yogurt. J. Dairy Sci., Savoy, v.60, p.13951398, 1977.

GOBbetti, M., CORSETTi, A., SMACCHI, E., ZOCCHETTI, A., De ANGELIS, M. Production of crescenza cheese by incorporation of bifidobacteria. $J$. Dairy Sci., Savoy, v.81, p.37-47, 1997.

GOLDIN, B.R. Health benefits of probiotics. Br. J. Nutr., Oxon, v.80, p.S203-S207, 1998.

GOMES, A.M.P., MALCATA, F.X. Development of probiotic cheese manufactured from goat milk: response surface analysis via technological manipulation. J. Dairy Sci., Savoy, v.81, n.6, p.1492-1507, 1998. 
GOMES, A.M.P., MALCATA, F.X. Bifidobacterium spp. and Lactobacillus acidophillus: biological, biochemical, technological and therapeutical properties relevant for use as probiotics. Trends Food Sci. Technol., Amsterdam, v.10, p.139-157, 1999.

GOMES, A.M.P., VIEIRA, M.M., MALCATA, F.X. Survival of probiotic microbial strains in a cheese matrix during ripening: simulation of rates of salt diffusion and microorganism survival. J. Food Eng., Oxford, v.36, p.281-301, 1998.

GUPTA, P.K., MITAL, B.K., GARG, S.K. Preparation and evaluation of acidophilus yogurt. J. Food Sci. Technol., Mysore, v.34, n.2, p.168-170, 1997.

HAVENAAR, R., BRINK, T., HUIS IN'T VELDT, J.H.J In: FULLER, R., ed. Probiotics: the scientific basis. London: Chapmann and Hall, 1992. p.209-224.

HICKEY, M.W., HILLIER, A.J., JAGO, G.R. Enzymatic activities associated with lactobacilli in dairy products. Aust.J. Dairy Technol., Melbourne, v.38, p.38-154, 1983.

HOLZAPFEL, W.H., HABERER, P., SNEL, J., SCHILLINGER, U., HUIS IN'T VELDT, J.H.J. Overview of gut flora and probiotics. Int. J. Food Microbiol., Amsterdam, v.41, p.85-101, 1998.

INGHAM, S.C. Use of modified Lactobacillus selective medium and Bifidobacterium iodoacetate medium for differential enumeration of Lactobacillus acidophilus and Bifidobacterium spp. in powdered nutritional products. J. Food Prot., Des Moines, v.62, n.1, p.77-80, 1999.

KAILASAPATHY, K., RYBKA, S. L. acidophilus and Bifidobacterium spp: their therapeutic potential and survival in yogurt. Aust. J. Dairy Technol., Melbourne, v.52, p.28-38, 1997.

KAILASAPATHY, K., SUPRIADI, D. Effect of whey protein concentrate on the survival of L. acidophilus in lactose-hydrolysed yoghurt during refrigerated storage. Milchwissenschaft, Muenchen, v.51, p.565-569, 1996.

KIM, H.S., GILLILAND, S.E. Lactobacillus acidophilus as a dietary adjunct for milk to aid lactose digestion in humans. J. Dairy Sci., Savoy, v.66, n.5, p.959-966, 1983.
KLAVER, F.A.M., KINGMAN, F., WEERKAMP, A.H. Growth and survival of bifidobacteria in milk. Netherland Milk Dairy J., Amsterdam, v.47, p.151-164, 1993.

KLEIN, G., PACK, A., BONAPARTE, C., REUTER, G. Taxonomy and physiology of probiotic lactic acid bacteria. Int. J. Food Microbiol., Amsterdam, v.41, p.103-125, 1998.

KNEIFEL, W., JAROS, D., ERHARD, F. Microflora and acidification properties of yoghurt and yoghurt-related products fermented with commercially available starter cultures. Int. J. Food Microbiol., Amsterdam, v.18, p.179-189, 1993.

KURMANN, J.A. Starters with selected intestinal bacteria. Bulletin IDF/FIL, Brussels, n.227, p.41-55, 1988.

KWAK, H.S., AHN, J.J., LEE, K.W., SUH, D.S. Flavor and sensory attribute in yogurt fermentation. Food Biotechnol., New York, v.5, n.2, p.94-98, 1996.

LANGHENDRIES, J.P., DETRY, J., VAN HEES, J., LAMBORAY, J.M., DARIMONT, J., MOZIN, M.J., SECRETIN, M.C., SENTERRE, J. Effect of a infant formula containing viable bifidobacteria on fecal flora composition and $\mathrm{pH}$ of healthy full-term infants. $J$. Pediatr. Gastroenterol. Nutr., Hagerstown, v.22, p.177$181,1995$.

LANKAPUTHRA, W.E.V., SHAH, N.P. A simple method for selective enumeration of Lactobacillus acidophilus in yogurt supplemented with $L$. acidophilus and Bifidobacterum spp. Milchwissenschaft, Muenchen, v.51, n.8, p.446-451, 1996.

LANKAPUTHRA, W.E.V., SHAH, N.P., BRITZ, M.L.L. Evaluation of media for selective enumeration of Lactobacillus acidophilus and Bifidobacterium species. Food Aust., Sydney, v.48, n.3, p.113-118, 1996.

LEE, Y.K., NOMOTO, K., SALMINEN, S., GORBACH, S.L. Handbook of probiotics. New York: Wiley, 1999. $211 \mathrm{p}$.

LORCA, G.L., RAYA, R.R., TARANTO, M.P., VALDEZ, G.F. Adaptative tolerance response in Lactobacillus acidophilus. Biotechnol. Lett., Dordrecht, v.20, n.3, p.239-241, 1998. 
MARSHALL, V.M. Fermented milks and their future trends. I. Microbiological aspects. J. Dairy Res., Cambridge, v.54, p.559-574, 1987.

MARSHALL, V.M.E., COLE, W.M., MABBITT, L.A. Yogurt made from single starter organisms using heattreated or enzyme-treated milk or milk to which casein hydrolysate or sodium formate is added. J. Dairy Res., Cambridge, v.49, p.147, 1982.

MATTILA-SANDHOLM, T., BLUM, S., GRENOV, G., ISOLAURI, E., KIELY, B., MARTEAU, P., MORELLI, L., OUWEHAND, A., RENIERO, R., SAARELA, M., SALMINEN, S., SAXELIN, M., SCHIFFRIN, E., SHANAHAN, F., VAUGHAN, E., VON WRIGHT, A. Probiotics: towards demonstrating efficacy. Trends in Food Sci. Technol., Amsterdam, v.10, p.393-399, 1999.

MATTILA-SANDHOLM, T. The PROBDEMO project: demonstration of the nutritional functionality of probiotic foods. Trends Food Sci. Technol., Amsterdam, v.10, p.385-386, 1999.

MICANEL, N., HAYNES, I.N., PLAYNE, M.J. Viability of probiotic cultures in commercial Autralian yoghurts. Aust. J. Dairy Technol., Melbourne, v.52, p.24-27, 1997.

MODLER, H.W. Bifidogenic factors: sources, metabolism and applications. Int. Dairy J., Amsterdam, v.4, n.5, p.383-407, 1994.

NAIDU, A.S., CLEMENS, R.A. Probiotics. In: NAIDU, A.S. Natural food antimicrobial systems. Boca Raton: CRC, 2000. p.431-462.

NIGHSWONGER, B.D., BRASHEARS, M.M., GILLILAND, S.E. Viability of Lactobacillus acidophilus and Lactobacillus casei in fermented milk products during refrigerated storage. J. Dairy Sci., Savoy, v.79, p.212-219, 1996.

NOGUEIRA, C., ALBANO, H., GIBBS, P., TEIXEIRA, P. Microbiological quality of portuguese yogurts. J. Ind. Microbiol. Biotechnol., Basingstoke, v.21, p.19-21, 1998.

O'BRIEN, J., CRITTENDEN, R., OUWEHAND, A.C., SALMINEN, S. Safety evaluation of probiotics. Trends Food Sci. Technol., Amsterdam, v.10, p.418-424, 1999.
OKAZAKI, T.Y., ALEGRO, J.H.A., ROCHA, J.S., SAAD, S.M.I. Microbiological profile of probiotic Minas cheese. In: CONGRESSO BRASILEIRO DE MICROBIOLOGIA, 21, Foz do Iguaçu, 2001. Resumos. Rio de Janeiro: Sociedade Brasileira de Microbiologia, 2001. p.389, res.AL-091.

OKSANEN, P., SALMINEN, S., SAXELIN, M., HÄMÄLÄINEN P., IHANTOLA-VORMISTO, A., MUURASNIEMI-ISOVIITA, L., NIKKARA, S., OKSANEN, T., PÖRSTI, T., SALMINEN, E., SIITONEN, S., STUCKEY, H., TOPPILA, A., VAPAATALO, H. Prevention of traveler's diarrhea by Lactobacillus GG. Annals of Medicine, Local?, v.22, p.53-56. 1990.

OLIVEIRA, M. N., LACERRA, A. A., GIOIELLI, L. A., BARUFFALDI, R. Effetto della temperatura e del tempo di coagulazione del latte sulla consistenza del formaggio "Minas Frescal" . In: PORRETA, S. Ricerche e innovazioni nell' 'industria alimentari. Pinerolo: Chiriotti Editora, 1996. v.2, p. 575-584.

OLIVEIRA, M. N., SODINI, I., REMEUF, F., TISSIER, J. P., CORRIEU, G. Manufacture of fermented lactic beverages containing probiotic cultures. J. Food Sci., Chicago, 2002. (no prelo)

OLIVEIRA, M.N., SODINI, I., REMEUF, F., CORRIEU, G. Effect of milk supplementation and culture composition on acidification, textural properties and microbiological stability of fermented milks containing probiotic bacteria. Intern. Dairy J., Amsterdam, v. 11/11-12, p. 935-942, 2001.

O’NEIL, J.M., KLEYN, D.H., HARE, L.B. Consistency and compositional characteristics of commercial yoghurts. $J$. Dairy Sci., Savoy, v.62, p.1032-1036, 1979.

OTT, A., HUGI, A., BAUMGARTNER, M., CHAINTREAU, A. Sensory investigation of flavour perception: mutual influence of volatiles and acidity. $J$. Agric. Food Chem., Columbus, v.48, p.441-450, 2000.

PATIDAR, S.K., PRAJAPATI, J.B. Standardisation and evaluation of lassi prepared using Lactobacillus acidophilus and Streptococcus thermophilus. J. Food Sci. Technol., Mysore, v.35, n.5, p.428-431, 1998. 
ROBERFROID, M.B. Concepts and strategy of functional food science: the European perspective. Am. J. Clin. Nutr., Bethesda, v.71, supl.6, p.1660-1664, 2000.

ROSSI, E.A. Formulação de um sucedâneo do iogurte a base de soro de leite e extrato aquoso de soja. Londrina, 1983. 74p. [Dissertação de Mestrado -Universidade Estadual de Londrina].

ROUSHDY, I.M., ALI, A.A., EL-KENANY, Y.M. Production of acidophilus and bifidus buttermilks from buffaloes'milk. Egypt. J. Food Sci., Cairo, v.24, n.2, p.233-246, 1996.

ROY, D., MAINVILLE, I., MONDOU, F. Selective enumeration and survival of bifidobacteria in fresh cheese. Int. Dairy J., Amsterdam, v.7, p.785-793, 1997.

RYBKA, S., FLEET, G.H. Populations of Lactobacillus delbrueckii spp. bulgaricus, Streptococcus thermophilus, Lactobacillus acidophilus and Bifidobacterium species in Australian yoghurts. Food Aust., Sydney, v.49, n.10, p.471-475, 1997.

RYBKA, S., KAILASAPATHY, K. The survival of culture bacteria in fresh and freeze-dried AB yogurts. Aust. $J$. Dairy Technol., Melbourne, v.50, p.51-57, 1995.

SAARELA, M., MOGENSEN, G., FONDÉN, R., MÄTTÖ, J., MATTILA-SANDHOLM, T. Probiotic bacteria: safety, functional and technological properties. $J$. Biotechnol., Amsterdam, v.84, p.197-215, 2000.

SALMINEN, S., VON WRIGHT, A., MORELLI, L., MARTEAU, P., BRASSART, D., de VOS, W.M., FONDÉN, R., SAXELIN, M., COLLINS, K., MOGENSEN, G., BIRKELAND, S.E., MATTILASANDHOLM, T. Demonstration of safety of probiotics: a review. Int. J. Food Microbiol., Amsterdam, v.44, p.93106, 1998.

SAMONA, A., ROBINSON, R.K. Effect of yogurt culture on the survival of bifidobacteria in fermented milks. $J$. Soc. Dairy Technol., London, v.42, n.2, p.58-60, 1994.

SAMONA, A., ROBINSON, R.K., MARAKIS, S. Acid production by bifidobacteria during fermentation and storage of milk. Food Microbiol., Kent, v.13, p.275-280, 1996.
SANDERS, M.E. Overview of functional foods: emphasis on probiotic bacteria. Int. Dairy J., Amsterdam, v.8, p.341347, 1998 .

SANDERS, M.E. Probiotics. Food Technol., Chicago, v.53, n.11, p.67-77, 1999.

SANDERS, M.E., KLAENHAMMER, T.R. Invited review: the scientific basis of Lactobacillus acidophilus NCFM functionality as a probiotic. J. Dairy Sci., Savoy, v.84, p.319-331, 2001.

SANDINE, W.E., MURALIDHARA, K.S., ELLIKER, P.R., ENGLAND, D.C. Lactic acid bacteria in food and health: a review with special reference to enteropathogenic Escherichia coli as well as certain enteric diseases and their treatment with antibiotics and lactobacilli. J. Milk Food Technol., Orange, v.35, n.12, p.691-702, 1972.

SAXELIN, M., GRENOV, B., SVENSSON, U., FONDÉN, R., RENIERO, R., MATTILA-SANDHOLM, T. The technology of probiotics. Trends Food Sci. Technol., Amsterdam, v.10, p.387-392, 1999.

SHAH, N.P. Bifidobacteria: characteristics and potential for application in fermented milk products. Milchwisshenschaft, Müenchen, v.52, p.16-21, 1997.

SHAH, N.P. Probiotic bacteria: selective enumeration and survival in dairy foods. J. Dairy Sci., Savoy, v.83, p.894$907,2000$.

SHAH, N.P., LANKAPUTHRA, W.E.V. Improving viability of Lactobacillus acidophilus and Bifidobacterium spp. in yogurt. Int. Dairy J., Amsterdam, v.7, p.349-356, 1997.

SHAH, N.P., RAVULA, R.R. Influence of water activity on fermentation, organic acid production and viability of yogurt and probiotic bacteria. Austr. J. Dairy Technol., Sidney, v.55, n.3, p.127-131, 2000.

SHORTT, C. The probiotic century: historical and current perspectives. Trends Food Sci. Technol., Amsterdam, v.10, p.411-417, 1999.

SREEKUMAR, O., HOSONO, A. Immediate effect of Lactobacillus acidophilus on the intestinal flora and fecal enzymes of rats and the in vitro inhibition of Escherichia coli in coculture. J. Dairy Sci., Savoy, v.83, n.5, 2000. 
STANTON, C., GARDINER, G., LYNCH, P.B., COLLINS, J.K., FITZGERALD, G., ROSS, R.P. Probiotic cheese. Int. Dairy J., Amsterdam, v.8, p.491-496, 1998.

STANTON, C., GARDINER, G., MUHAN, H., COLLINS, K., FITZGERALD, G., LYNCH, P.B., ROSS, R.P. Market potential for probiotics. Am. J. Clinical Nutr., Bethesda, v.73, supl.6, p. 476-1835, 2001.

STIEN, G., BLANCHARD, F., RONDAGS, E., MARC, I. Une méthode de dosage en ligne du diacétyle et de l' acétaldéhyde dans les yaourts, laits fermentés, beurres et margarines. Lait, Les Ulis, v.79, p.615-624, 1999.

SVENSSON, U. Industrial perspectives. In: TANNOCK, G.W. Probiotics: a critical review. Wymondham: Horizon Scientific, 1999. p.57-64.

TEJADA-SIMON, M.V., LEE, J.H., USTUNOL, Z., PESTKA, J.J. Ingestion of yogurt containing $L$. acidophilus and Bifidobacterium to potentiate immunoglobulin A responses to cholera toxin in mice. $J$. Dairy Sci., Savoy, v.82, p.649-680, 1999.

VINDEROLA, C.G., BAILO, N., REINHEIMER, J.A. Survival of probiotic microflora in Argentinian yoghurts during refrigerated storage. Food Res. Int., Amsterdam, v.33, p.97-102, 2000a.
VINDEROLA, C.G., PROSELLO, W., GHIBERTO, D., REINHEIMER, J.A. Viability of probiotic (Bificobacterium, Lactobacillus acidophilus and Lactobacillus casei) and nonprobiotic microflora in Argentinian fresco cheese. J. Dairy Sci., Savoy, v.83, p.1905-1911, 2000b.

VINDEROLA, C.G., REINHEIMER, J.A. Enumeration of $L$. casei in the presence of $L$. acidophilus, bifidobacteria and lactic starter bacteria in fermented dairy products. Int. Dairy J., Amsterdam, v.10, n.4, p.271-275, 2000c.

VINDEROLA, C.G., PROSELLO, W., GHIBERTO, D., REINHEIMER, J.A. Viability of probiotic (Bifidobacterium, Lactobacillus acidophilus and Lactobacillus casei) and nonprobiotic microflora in Argentinian fresco cheese. J. Dairy Sci., Savoy, v.83, p.1905-1911, 2000c.

ZIEMER, C.J., GIBSON, G.R. An overview of probiotics, prebiotics and synbiotics in the functional food concept: perspectives and future strategies. Int. Dairy J., Amsterdam, v.8, p.473-479, 1998.

Recebido para publicação em 29 de junho de 2001. 